\title{
Real-time fMRI neurofeedback as a new treatment for psychiatric disorders: a meta-analysis
}

\author{
Pamela Pindi $^{1,2}$, Josselin Houenou ${ }^{1,2^{*}}$, Camille Piguet ${ }^{3}$, Pauline Favre ${ }^{1,2}$
}

${ }^{1}$ Paris Est Créteil University (UPEC), INSERM U955, IMRB, Translational Neuro-psychiatry team, AP-HP, DMU IMPACT, Henri Mondor Hospital, FondaMental Foundation, F-94010 Créteil, France

${ }^{2}$ Paris-Saclay University, Neurospin, CEA, clinical unit (UNIACT), 91191, Gif-sur-Yvette, France

${ }^{3}$ Department of Psychiatry, Faculty of Medicine, University of Geneva \& Campus Biotech, Geneva, Switzerland

*Corresponding author:

Josselin Houenou, MD, PhD

Neurospin, CEA Saclay, France

91191, Gif-sur-Yvette, France

Email: josselin.houenou@inserm.fr 
Keywords: Real-time fMRI, Neurofeedback, Psychiatric disorders, Functional Magnetic Resonance Imaging, Brain-computer interface, neuroimaging

\begin{abstract}
Neurofeedback using real-time functional MRI (RT-fMRI-NF) is an innovative technique that allows to voluntarily modulate a targeted brain response and its associated behavior. Despite promising results in the current literature, its effectiveness on symptoms management in psychiatric disorders is not yet clearly demonstrated. This meta-analysis aims to evaluate the clinical effectiveness of RT-fMRI-NF in the treatment of psychiatric disorders and to provide methodological suggestions for future studies. Web of Science and PubMed databases were searched using the keywords: neurofeedback AND (fMRI OR "functional magnetic resonance imag*" OR "functional MRI") AND ("real-time" OR "real time"). Thirty-one clinical trials focusing on psychiatric disorders were included and categorized according to standard diagnostic categories. The RT-fMRI-NF efficacy was assessed by reporting changes in clinical endpoints before vs. after NF training and before or after NF training vs. follow-up. Among the 31 identified studies, 22 consisted of controlled trials, of which only eight showed significant clinical improvement in the experimental vs. control group after the training. Nine studies found an effect at follow-up on ADHD symptoms, emotion dysregulation, facial emotion processing, depressive symptoms, hallucinations, psychotic symptoms, and specific phobia. Within-group meta-analysis revealed large effects of the NF training on depressive symptoms right after the training $(g=0.84, \mathrm{p}<0.01)$ and at follow-up $(g=1.25, \mathrm{p}<0.01)$, as well as medium effects on anxiety $(g=0.52, \mathrm{p}=0.01)$ and emotion regulation $(g=0.46, \mathrm{p}=0.01)$. Between-group metaanalysis showed a medium effect on depressive symptoms $(g=0.46, p<0.01)$ and a large effect on anxiety $(g=0.91, \mathrm{p}=0.09)$. However, the between-studies heterogeneity is very high. The use of RT-fMRI-NF as a treatment for psychiatric symptoms is promising, however, further double-blind, multicentric, randomized-controlled trials are warranted.
\end{abstract}




\section{Introduction}

Psychiatric disorders are a major global health problem because of their high prevalence and burden (1). While the development of pharmacological treatments gradually fades away (1), new stimulation techniques that directly target brain activity are emerging. However, most of these techniques, - such as deep brain stimulation (2), repetitive transcranial magnetic stimulation (3) or transcranial direct current stimulation (4) - require physical interventions. In this context, real-time functional magnetic resonance imaging neurofeedback (RT-fMRI-NF) has recently gained interest in the neuroscientific community as a novel, non-invasive, treatment for psychiatric disorders. Neurofeedback (NF) is a type of biofeedback that aims to measure neural activity in a specific brain region and presents it back to the participants in realtime using a visual, auditory or another symbolic representation (5). Through this feedback, participants can learn to intentionally regulate their brain activity and indirectly the related cognitive processing.

Primarily developed in combination with electroencephalographic (EEG) recordings, neurofeedback opened a new way for the neuroscientific community to tackle neurological and psychiatric disorders (6-8). In the first proof-of-concept, Lubar et Lubar (1984) provided two sessions of EEG neurofeedback training to children with ADHD by targeting the sensorimotor rhythm and the beta activity. All children showed an improvement in academic performance after the NF training (8). Later, Heinrich et al., (2004) demonstrated a reduction of ADHD symptomatology by $25 \%$ in 13 children after a slow cortical potential training (6). However, EEG-NF offers only an approximate localization of active brain regions, which is a critical key for successful neurofeedback training, and very limited access to deep subcortical brain areas that are involved in the pathophysiology of many psychiatric disorders (9).

MRI has the advantage of a high spatial resolution, allowing whole-brain activity recordings including subcortical regions. This technique relies on the measure of the hemodynamic response of blood oxygen level-dependent (BOLD signal), which is considered as an indirect measure of neuronal activity (10). Functional MRI-based NF has been used to modulate the behavior by increasing or decreasing the activity in cortical and subcortical region of interest (ROI). The implementation of RT-fMRI provides image processing as fast as image acquisition (11-13), which in turn enables analysis of the entire brain activity within a very short delay and, with an appropriate feedback, to provide guidance to the participants to regulate their own brain activity (13) (see Figure 1). 


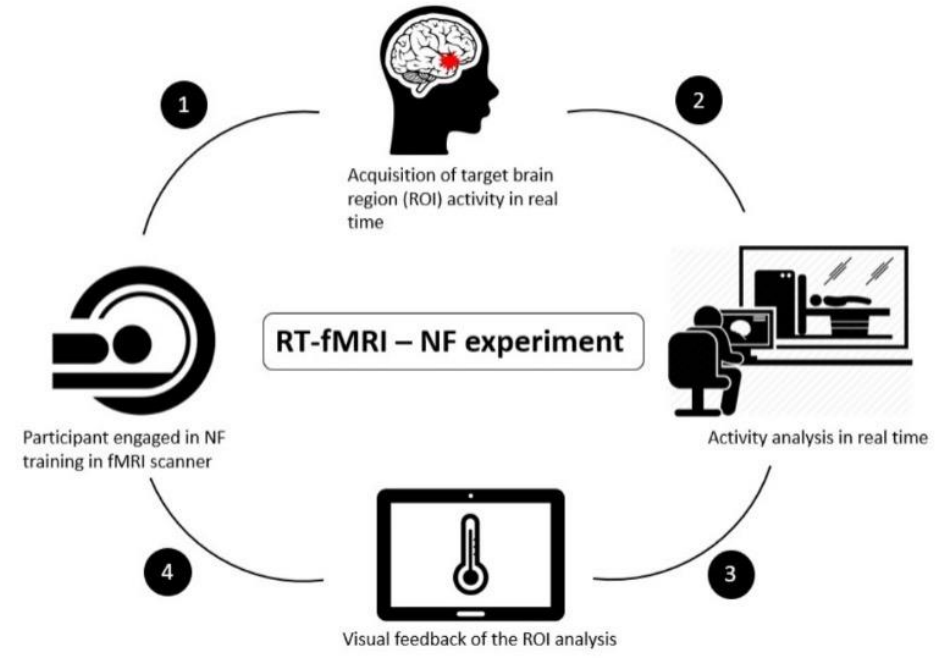

Figure 1. Symbolic representation of an RT-fMRI-NF experiment with a thermometer display as visual feedback on brain activity

First studies demonstrated the effectiveness of RT-fMRI-NF on the relief of neurological symptoms such as chronic pain (14) or tinnitus (15). In psychiatry, recent advances in neuroscience and neurophysiology allowed to incriminate brain regions and networks that might underlie the pathophysiology of various psychiatric disorders. Normalizing these aberrant activations is therefore a key issue for new treatments aiming at reducing the intensity of the symptoms associated with psychiatric diseases (16).

While more and more studies attempt to use RT-fMRI-NF in the treatment of psychiatric disorders, the clinical effectiveness is not yet clearly demonstrated, especially because of the diversity of the methods, designs, and outcomes measurement. Previous literature reviews that focus on depression demonstrated the efficacy of RT-fMRI-NF with a medium effect size on neural activity during NF training, a large effect size on the transfer run (when the feedback is absent) and small effect sizes on behavioral outcomes (17). They also demonstrated the clinical effectiveness of the technique in the management of depressive symptoms (18). While these studies provide cumulative evidence for the efficacy of neurofeedback in both neural regulation and clinical symptoms improvement in depressive disorders, we still do not know how effective this technique is in other psychiatric disorders or whether the clinical effects observed after training are maintained over time. In this context, the main aims of our meta-analysis are (1) to assess the efficacy of RT-fMRI-NF qualitatively and quantitatively on the improvement of clinical symptoms in various psychiatric disorders, (2) to discuss the methods used in these studies and (3) to provide methodological suggestions for future clinical trials aiming at using RT-fMRI-NF as a therapeutic tool in psychiatric disorders. 


\section{Methods}

\subsection{Materials}

This meta-analysis was conducted according to the Preferred Reporting Items for Systematic Reviews and Meta Analyses (PRISMA) guidelines (19). Studies were identified until October $19^{\text {th }}, 2021$ through a search within two databases, PubMed and Web of Science, using the following keywords: neurofeedback AND (fMRI OR "functional magnetic resonance imag*" OR "functional MRI") AND ("real-time" OR "real time"). To be included in our qualitative synthesis, the articles had to meet the following criteria: 1) focusing on psychiatric disorders as defined by common psychiatric disorders classifications (e.g., DSM-IV (20), DSM5 (21) or ICD-10 (22) and clinical interviews such as the MINI (23) or the SCID (24)). Only one study did not report the use of common psychiatric classification but directly recruited inpatients admitted for a major depressive episode (25);2) aiming at improving the clinical symptoms related to a given psychiatric disorder; 3) participants had to regulate their brain activity based on the feedback signal from a given region of interest (ROI) or set of ROIs or the functional connectivity between two or more ROIs, which was recorded in real time with fMRI.

After duplicate removal, we initially identified 508 records. Among them, 293 were excluded based on title and abstract. Precisely, we excluded 65 articles not directly related to RT-fMRINF (e.g., performed neurofeedback with a different imaging modality), 137 proceedings, abstracts, or methods articles, 75 reviews, 8 articles published in a language other than English, and 8 secondary analyses of a previously published dataset. We screened the full text of the 215 remaining articles and removed 184 of them because they did not meet our inclusion criteria, mainly because they did not include psychiatric disorders or did not assess symptom severity in the outcomes. We also excluded studies focusing on non-pathological substance abuse $(24,26,27)$. The final sample includes 31 studies (see Figure 2). The summary of this studies can be found in Table 1 . 

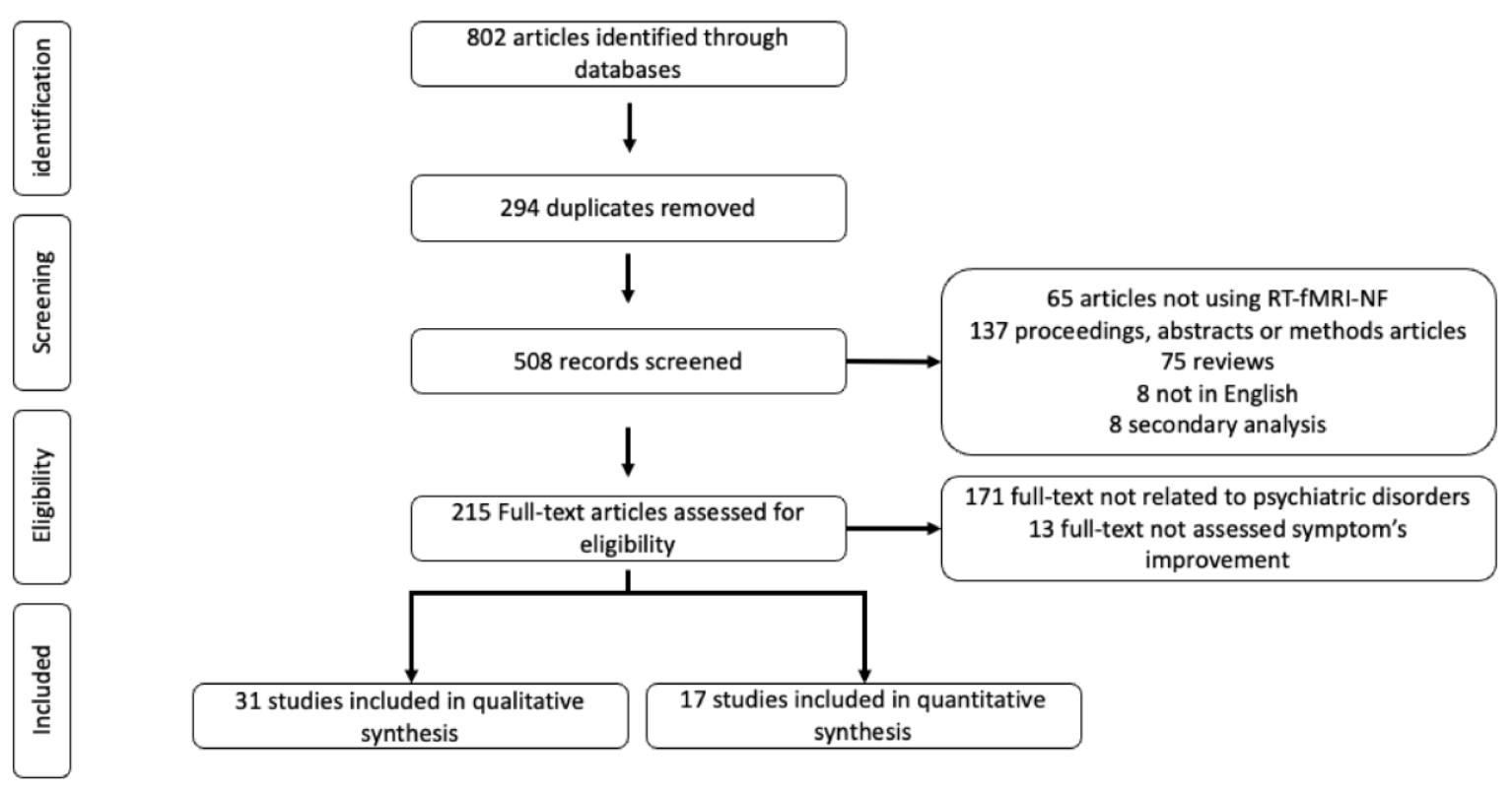

Figure 2. Flow Chart of included studies

\section{INSERT TABLE 1 HERE}

\subsection{Clinical effectiveness report}

Two types of contrasts were evaluated to highlight the effects of NF training in each reviewed study: 1. Training effect describes the clinical effectiveness significance of NF training on the outcome measure between the baseline (i.e., the first session/run) and the primary endpoint (i.e., the last session if it's a multiple-sessions training; or the last run if it's a single-session training). 2. Follow-up effect describes the sustained symptoms improvement beyond the NF training period. For both training effect and follow-up effect, effect sizes of within-group and betweengroup comparisons were reported with Hedge's $g$. The between group effect size was based on the differences in clinical outcome between the experimental and control groups. Control groups were either active or no-intervention, depending on design study. Methods and formulas used for the conversion to Hedge's $g$ are reported in Supplementary Materials.

2.3.Meta-analysis of the effect of NF on clinical symptoms 
We performed a within-experimental group analysis and a between-group analysis. Papers were included in within-experimental group analysis if they explicitly reported data, $\mathrm{T}$ or $\mathrm{F}$ values. They were included in between-group analysis only if data were available online. In case, these were not reported or extractable from the reported data in the paper, we reached out to the corresponding authors, requesting this information. If these data were supplied, the paper was included in the final analysis. For all sources that met inclusion criteria, effect sizes, 95\% confidence intervals, and their standard errors were calculated using "dmetar" software package in R 2021.09.2+382 (https://bookdown.org/MathiasHarrer/Doing_Meta_Analysis_in_R/). For standardization, all effect sizes were transformed in Hedge's g metric using "esc" software package (https://CRAN.R-project.org/package=esc) (28). As we anticipated between-study heterogeneity, a random-effects model was used to pool effect sizes $(29,30)$. The restricted maximum likelihood estimator (31) was used to calculate the heterogeneity variance $\tau^{2}$, that quantifies the variance of the true effect sizes underlying our data. We used Knapp-Hartung adjustments (32) to calculate the 95\% confidence interval around the pooled effect. The summary statistics of the meta-analysis included several indices. First, overall effect; a weighted mean pooled from all studies included in the analysis. The coefficient weight for each study was calculated based on the confidence interval of the estimated effect, influenced by the study's sample size. Then, the $\tau^{2}$ and the $\mathrm{I}^{2}$ statistic, that accounts for variability in effect sizes that is not due to sampling error (33). To evaluate the heterogeneity, we performed an outlier and influence analyses using "dmetar" package and a leave-one-out method to obtain the influence of each study on the pooled effect, which is recalculated with one study omitted each time. Results of these analyses are reported in Supplementary Results.

\section{Results}

\subsection{Included studies}

We identified 31 articles that evaluated the efficacy of RT-fMRI-NF in psychiatric disorders. Among them, 11 concerned mood disorders (25,34-43), 5 psychotic disorders (4448), 5 trauma or stress-related disorders (41,49-52), 4 neurodevelopmental disorders (53-56), 3 addiction disorders (57-59), 2 personality disorders $(60,61)$ and 1 anxiety disorders $(62)$. Out of the 31 studies, 22 were controlled studies (see Figure $3 \mathrm{~A}$ and Table 1). 
A.

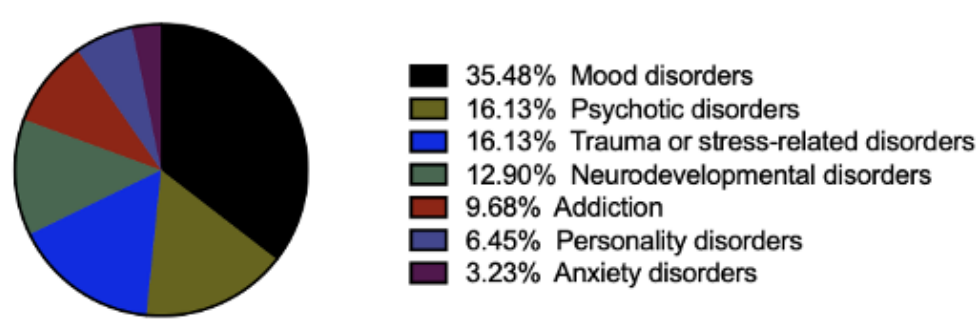

B.
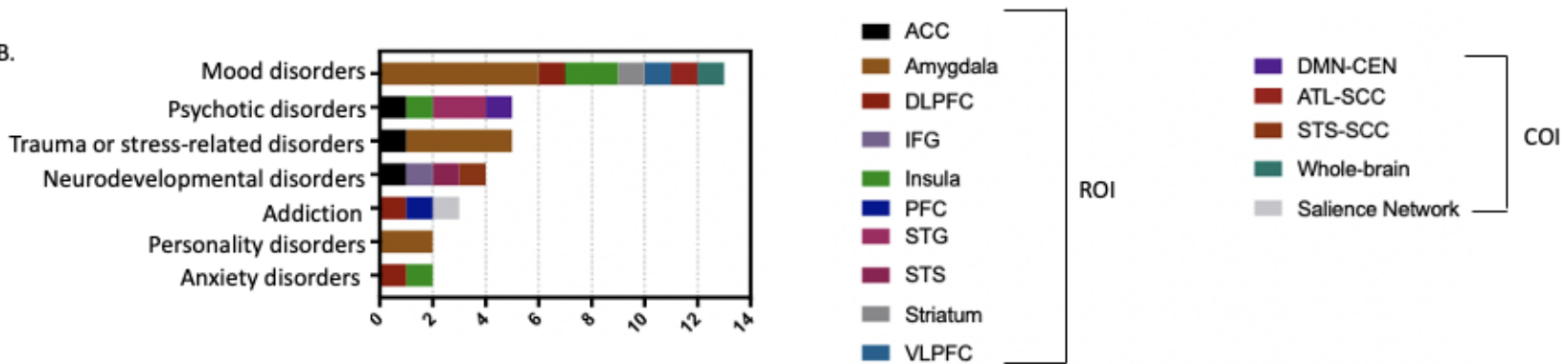

Figure 3. Distribution of the reviewed studies according to the category of psychiatric disorders (A) and the region of interest (ROI) or the connectivity of interest (COI) selected for the NF training (B). NB: abbreviations used in figure are defined in Table 1's footnote. If an experiment focused on more than one ROI, we included both in the figure (thus, the total number of ROIs exceeds the total number of studies).

Targeting specific ROIs is the most represented strategy (26 out of the 31 studies) all conditions combined (see Figure3B). Most of them focused on modulating the activity of the amygdala (AMY; 12 studies), followed by the insula (4 studies), and the anterior cingulate cortex (ACC; 3 studies). Studies on mood disorders targeted a wide variety of ROIs located in cortical (mainly the prefrontal cortex PFC) $(25,34)$ and subcortical areas (mainly the AMY) involved in depression and emotion processing (37-39,42,43,63), while those focusing on personality disorders only targeted the AMY $(60,61)$. The study on anxiety disorders used a feedback derived from the fronto-insular connectivity (62). Studies on psychotic disorders rather focused on ROIs involved in auditory hallucinations symptoms, such as the superior temporal gyrus (STG) $(46,47)$, the default mode network (DMN) (44), and the ACC (45). Regarding neurodevelopmental disorders, studies that focused on ADHD symptoms targeted hyperactivity and attention via the modulation of the inferior frontal gyrus (IFG) (53) and the ACC activity (55), respectively. In contrast, one study on ASD targeted social processing via the connectivity between the left superior temporal sulcus (STS) and the left somatosensory 
cortex (SC) (54). The other targeted the facial emotion expression processing via the right posterior STS activity (56). Trauma and stressor-related disorders studies focused on the modulation of AMY $(41,49,50,52)$ and the ACC (51) because of their implication in emotion dysregulation, a key symptom in PTSD. Addiction studies targeted the PFC $(57,58)$ and salience network (64), which is involved in craving and decision-making (see Figure3B and Figure4).

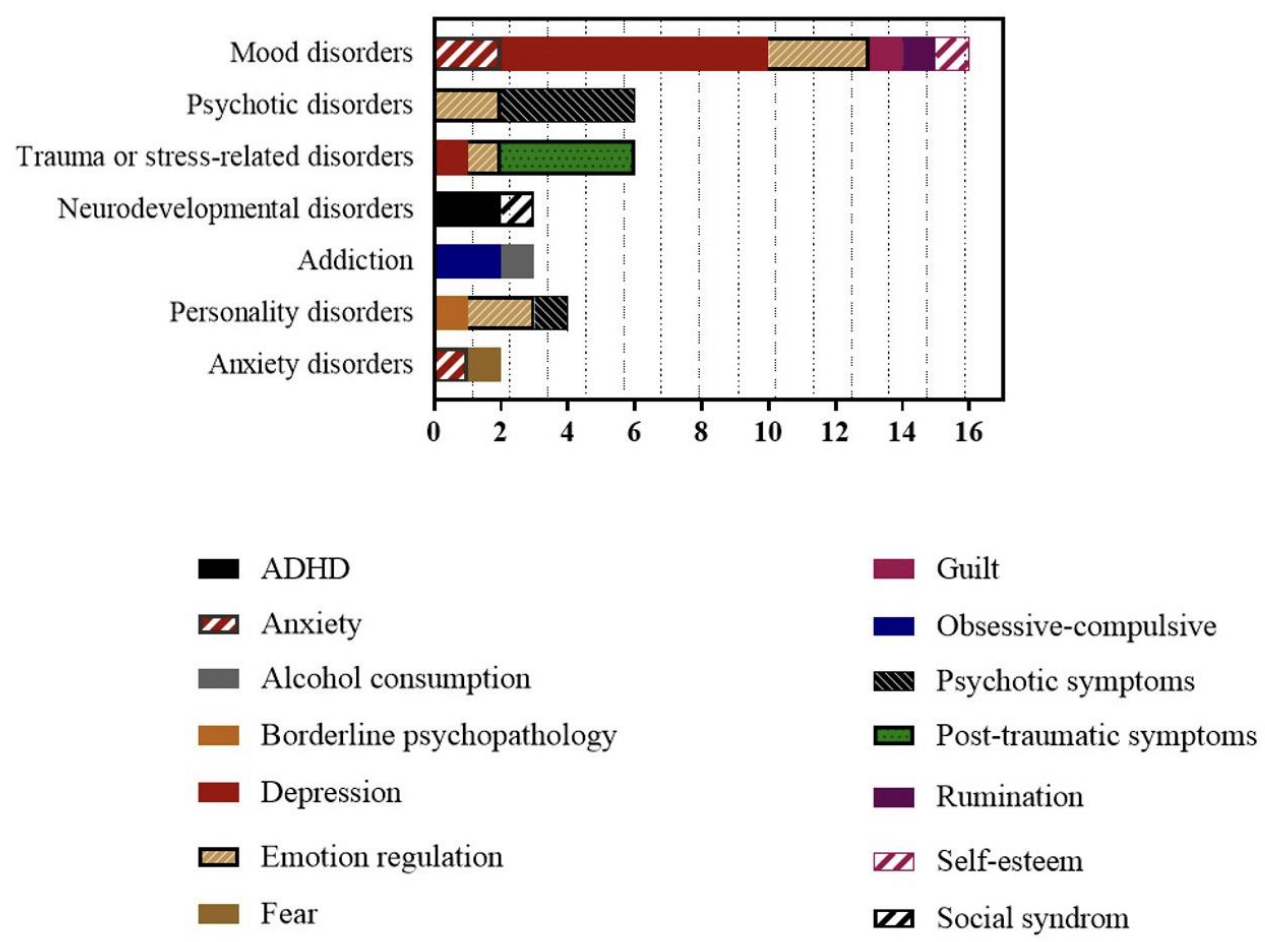

Figure 4. Symptoms targeted among the category of psychiatric disorders

\subsection{Neurofeedback paradigms and clinical efficacy in psychiatric disorders}

The reviewed studies employed different types of paradigms, tasks, and self-regulation protocols to train participants to either up- or downregulate the BOLD signal (or connectivity) in brain areas involved in a given disorder. Specific symptoms changes induced by the RTfMRI-NF training are summarized in Table 2 and Table 3 and detailed for each pathology below. 


\subsubsection{Mood disorders}

The most widely used paradigm in RT-fMRI-NF studies of mood disorder consists of recalling positive autobiographical memories (6 out of 11 studies), in order to increase amygdala activity and thus to treat symptoms related to emotion dysregulation $(37,42,63)$, depression $(38,39,43)$ and anxiety $(39,42)$.

In a first proof-of-concept study of RT-fMRI-NF in MDD, Linden et al. (2012) compared two groups of patients with MDD ( $n=8$ in each group). While the patients with MDD in the active control group performed a mental imagery task involving positive emotions outside the scanner, patients of the experimental neurofeedback group attempted to upregulate regions involved in positive emotions during four three-runs NF-training sessions. Patients in the neurofeedback group showed a significant decrease in depressive symptoms $(g=1.33)$, which was significantly higher than in the control group (34). In one recent study, Mehler et al. (2018) used a larger sample with 16 patients in each group. Patients in the active control group were trained to upregulate regions activated by visual scenes while patients in the experimental group tried to upregulate areas involved in emotion processing during a two six-runs NFtraining sessions. Depressive scores were reduced in both groups after the NF training (CG: $g$ $=2.16$; EG: $g=2.23$ ) with a sustained improvement at 1-month follow-up. Similar effects were observed for anxiety levels but only patients in the experimental group showed a sustained improvement in depressive symptoms at follow-up ( $g=1.57)(35)$.

In a set of six studies, patients with MDD were trained to upregulate amygdala activity. In the first studies by Young et al. (2014) and Yuan et al. (2014), patients were instructed to recall positive autobiographical memories during a single three-runs NF-training session. Patients with MDD in the active control group received feedback from an unrelated region in the parietal lobe. Participants in the experimental group showed significant decrease in depressive and anxiety scores (37,39) as well as in anger level (37). In Young et al. (2014), the patients also showed increased happiness, as assessed by a happiness visual scale, which was significantly greater than in the control group $(g=0.36)$ (37). Patients with MDD in Zotev et al. (2016) performed the same neurofeedback and self-regulation task during two three-runs sessions of neurofeedback. They also presented less depressive and mood symptoms and a significant increase in happiness. The active experimental group showed a significant decrease in depressive score compared to the control group after the NF training ( $g=0.03)$ (63). In a 
more recent study (2020), the same authors were able to replicate these results with a greater sample in the experimental group and by targeting the rostro-dorsal ACC. They showed a significant decrease in depression score $(g=-0.59)$, and in state anxiety $(g=-0.54)$ and a significant increase in happiness $(g=0.56)$ in the experimental group (42). Using the same paradigm, Young et al. (2017) revealed a significant decrease in depressive score in the active experimental group compared to the control group (significant group-by-time interaction) after the training $(g=1.13)$. They also showed a significant sustained decrease in depression score at 1-week follow-up in patients with MDD (within-group analyses: $g=0.58$ for MADRS; between-group analyses: $g=1.14$ for MADRS, $g=0.72$ for BDI-II, $g=0.90$ for HAM-D) (38). Similarly, Tsuchiyagaito et al. (2020) showed a sustained improvement of depressive symptoms at 2-weeks follow-up ( $g=0.54$ ) (43).

In a double-blind proof-of-concept study, remitted patients with MDD attempted to upregulate the connectivity between the anterior temporal lobe (ATL) and the subgenual cingulate cortex (SCC) during a single two-run neurofeedback training session by retrieving guilt and indignation/anger-related autobiographical memories. Participants in the experimental group showed increased self-esteem and decreased self-hatred at higher levels than the control group at the end of the training (significant group-by-time interaction) (40). Recently, in Mennen et al. (2021) study, patients underwent an emotional induction task within a three seven-to-nine-runs NF-training sessions of neurofeedback. Authors demonstrated a significant decrease in depressive symptoms after the NF training $(g=1.28)$ with a sustained improvement at 1-month $(\mathrm{g}=1.05)$ and 3-month follow-up $(g=1.30)(36)$.

\subsubsection{Psychotic disorders}

In schizophrenia, authors focused either on the emotion dysregulation (48) or on auditory hallucinations (44-47).

In the first proof-of-concept of RT-fMRI-NF in schizophrenia, Ruiz et al. (2013) taught patients to upregulate the anterior insula in a 12-session neurofeedback training while performing a face emotion recognition task. Patients showed a decrease in negative affect and an increase in positive affect as measured by the PANAS at primary endpoint (48).

In the four other studies, authors focused on the treatment of auditory hallucinations by targeting different cerebral networks. In a pilot study, Dyck et al. (2016) reported various effects of neurofeedback training in three patients who tried to upregulate ACC during three sessions. In most cases, patients reported perceiving fewer negative voices and more positive voices with 
a decrease in disturbance by and suffering from voices. Those effects remained constant few days after training. (45). Orlov et al. (2019) trained patients with SZ to downregulate the left superior temporal gyrus during four sessions of neurofeedback. Patients showed a significant decrease in beliefs regarding the origin of voices $(g=0.59)$ and in the intensity of distress perceived $(g=0.60)$ after the NF training. At 1-week follow-up, patients showed a sustained improvement in the beliefs about origins (47). While using the same neurofeedback paradigm, Okano et al. (2020) showed a significant decrease in auditory hallucinations in patients with SZ after the training ( $g=1.72$ ) (46). Bauer et al. (2020) revealed a significant sustained decreased in the frequency of auditory hallucinations after downregulation of the DMN connectivity at 1week follow-up $(g=0.53)(44)$.

\subsubsection{Trauma- and stressor-related disorders}

In the first studies regarding PTSD, patients attempted to downregulate amygdala activity within three sessions of NF-training while hearing trauma-related scripts (49) or watching trauma-related words (50). Gerin et al. (2016) showed a significant decrease in patients' symptomatology at primary endpoint (49). However, Nicholson et al (2017) did not report a difference in PTSD symptoms (50).

In two single-blinded proof-of-concept studies, patients with PTSD in the active control group received feedback from a brain region not related to PTSD symptoms and patients in the experimental group were trained to upregulate the amygdala activity by recalling positive autobiographical memories (52) or by undergoing an happy emotion induction task (41). Both studies showed a significant decrease in PTSD symptoms (Clinician Administrated PTSD scale (CAPS) total score $: g=-1.80$ (52), $g=-1.79$ (41); CAPS avoidance symptoms $: g=-1.84$; CAPS hyperarousal symptoms subscale $: g=-1.23(41)$ ) and a significant decrease in depressive scores (MADRS : $g=-1.68$ (52); HDRS : $g=-2.24$ (41)) in the experimental group at the primary endpoint.

In Zweering et al. 2018, patients with PTSD and healthy participants attempted to upregulate the ACC by performing mental imagery during three sessions of neurofeedback training. The authors showed a significant decrease in intrusion score $(g=1.64)$ and in negative affect, as well as a significant increase in positive affect in the experimental group with a groupby-time interaction at primary endpoint $(g=1.05)(51)$.

\subsubsection{Neurodevelopmental disorders}


In the first single-blinded study assessing the efficacy of RT-fMRI-NF in neurodevelopmental disorders, Ramot et al. (2017) attempted to bring connectivity level between networks, in patients with ASD, closer to those of TD patients. While patients with TD were trained to reinforce the connectivity between the STS and the inferior temporal lobe (two regions as uncorrelated as possible), patients with ASD were trained to upregulate the connectivity between the STS and the SCC during four neurofeedback sessions. All started with a blank screen and were instructed to reveal the picture hidden underneath. This was described as a puzzle task and no further instructions were given. ASD patients showed a significant reduction in autistic traits after NF training (54). Later Direito et al. (2021) showed a significant improvement in fear recognition after the NFB training and at 6-months follow-up in ASD patients after five four-run neurofeedback training sessions while targeting the right posterior STS during an emotion recognition task. They also showed a decrease in depressive score and anger after the primary endpoint (56).

Alegria et al. (2017) compared two groups of adolescents with ADHD during four neurofeedback training sessions. The control group received feedback from the parahippocampal gyrus, a region unrelated to the symptomatology, and the patients in the experimental tried to upregulate the inferior frontal gyrus activity. Authors showed a significant decrease in ADHD scores (ADHD total score: $g=0.59$; ADHD inattention subscale: $g=0.65$ ) and a slight decrease in hyperactivity/impulsivity in the experimental group at primary endpoint $(g=0.43)$. The decrease in ADHD symptoms were significantly maintained at follow-up in the experimental group (ADHD total score: $g=0.88$; ADHD hyperactivity: $g=0.87$ ). Both groups showed a decrease in ADHD severity and only the experimental group control showed significant decrease in ADHD-related difficulties and impairments (53).

In a randomized single-blinded study, Zilverstand et al. (2017) trained the experimental group and the active control group to upregulate the ACC while performing mental calculation during four sessions of neurofeedback training. Patients in the experimental group were the only one to receive continuous feedback from the ACC. Both groups showed a decrease in impulsivity and improved performance in a cognitive interference task. Only the experimental group showed an increase in attention, in response inhibition and in visual working memory after the NF-training (55).

\subsubsection{Addiction}


Among the three studies concerning addiction, two focused on alcohol use disorder (AUD) and one on nicotine use disorder. Karch et al. (2015) compared two groups of patients with AUD and one group of healthy participants performing an alcohol-cue induced craving task during a single four-run neurofeedback training session. The healthy control group was divided into two groups according to the region of interest used for the feedback calculation: one group received feedback from the PFC (experimental) and one group from the cuneus (control). Authors showed a decrease in subjective craving scores in the experimental group at primary endpoint (58). Later, Subramanian et al. (2021) compared an active control group with "treatment as usual" (TAU) (i.e., psychoeducation, psychological support, and medical management of abstinence) to an experimental group with TAU and six two-run neurofeedback training sessions. They were trained to downregulate the activity of the salience network with an alcohol-cue induced craving. The authors found a significant decrease in alcohol consumption in the experimental group at primary endpoint. At 8-months follow-up, they showed a greater decrease in alcohol consumption in the control group. At 12-month followup, the trend was reversed, the patients of the experimental group showed a greater decrease in alcohol consumption in comparison to the control group (59).

Hartwell et al. (2016) assessed the efficacy of the RT-fMRI-NF in nicotine-use disorder with a smoking-cue exposure task. They used a control group composed of patients that did not receive feedback and an experimental group composed of patients who were trained to downregulate the PFC during three three-run neurofeedback training sessions. Patients in the experimental group showed a significant craving decrease $(g=0.61)$, especially regarding the anticipation of the pleasurable outcomes of smoking $(g=0.65)$ at primary endpoint $(57)$.

\subsubsection{Personality disorders}

Two studies focusing on borderline personality disorder (BPD) were conducted. Both did not include a control group. Patients with BPD were trained to downregulate the activity of the amygdala while watching negative and neutral pictures during four three-runs NF-training sessions (61) and three four-runs NF-training sessions (60). In Paret et al. (2016), the authors showed a significant decrease in emotion dysregulation (Difficulties in Emotion Regulation Scale (DERS) lack of emotional awareness subscale: $g=1.27$ ) and in dissociation symptoms $(g=1.97)$ at primary endpoint. Results were sustained 3-days after the training (60). In Zaehringer et al. (2019), patients with BPD showed a significant decrease in symptom severity ( $g=0.63)$, which was sustained at 6-weeks follow-up $(g=0.44)$. They also demonstrated a 
decrease in alexithymia and affective instability. At follow-up, patients showed a significant decrease in emotion dysregulation $(g=0.47)$, a significant increase in emotional skills $(g=-$ $0.54)$ and a decrease in alexithymia (61).

\subsubsection{Anxiety disorders}

Zilverstand et al. (2015) assessed the anxiety symptoms related to spider phobia. They used an active control group of patients who were told to use an intuitive strategy and an experimental group of patients who were instructed to use reappraisal strategies during an anxiety provocation task. Both groups were trained to upregulate the activity of the dorsolateral PFC and to downregulate the insula during four single-run NF-training sessions. Authors showed significant decrease in anxiety levels in both groups with lower average anxiety in the experimental group, as well as a significant group-by-time interaction $(g=2.59)$ at primary endpoint. At follow-up, both groups showed a decrease in spider phobia (62).

\section{INSERT TABLE 4 HERE}

\subsection{Meta-analysis of clinical improvement in the experimental groups}

Seventeen studies were included in this meta-analysis (see Table 5). Within-experimental group analysis was performed for depressive symptoms, anxiety symptoms and emotion regulation improvement at the end of NF training. Only depressive symptom's improvement was evaluated at follow-up. Between-group analysis was conducted only in controlled studies assessing the depressive symptoms and the anxiety symptoms.

\subsubsection{Within-experimental group analysis}

The results of within-experimental group analysis showed a significant effect, with a large effect size for the depressive symptoms improvement after NF training measured by withinexperimental-group differences in depressive score between the baseline and the primary endpoint across 13 studies ( $g=0.8495 \%$-CI $[0.52 ; 1.16], \mathrm{T}=5.42, \mathrm{p}<0.01)$ (see Figure 5 top). A large effect size for the depressive score is also observed between the baseline and the followup across 4 studies ( $g=1.25,95 \%$-CI [0.6216; 1.8698], $\mathrm{T}=5.54, \mathrm{p}<0.01)$ (see Figure 6). The anxiety improvement and emotion regulation improvement after NF training yielded a medium 
effect size (respectively: $g=0.52,95 \%$-CI [0.19-0.85], $\mathrm{T}=4.43, \mathrm{p}=0.01 ; g=0.46,95 \%$-CI [0.17-0.76], $\mathrm{T}=4, \mathrm{p}=0.01$ ) across 5 studies each (see Figure 5 middle and bottom).

The between-study heterogeneity variance was estimated at $\tau^{2}=0.07$ (95\%-CI [0;0.7020]), with a heterogeneity factor $\mathrm{I}^{2}$ value of $42,5 \%(95 \%$-CI $[0 \% ; 70 \%], \mathrm{p}=0.05)$, revealing a significant between-study variance for the depressive symptom meta-analysis. The betweenstudy variance did not reached a significant level for the anxiety symptom $\left(\tau^{2}=0,95 \%\right.$-CI [0.0000; 0.5143]; $\mathrm{I}^{2}=0,95 \%$-CI $\left.[0.0 \% ; 79.2 \%], \mathrm{p}=0.76\right)$ and for the emotion regulation analyses $\left(\tau^{2}=0,95 \%\right.$-CI $[0.0000 ; 0.3250] ; \mathrm{I}^{2}=0,95 \%$-CI $[0.0 \% ; 74.6 \%], \mathrm{p}=0.53$ ) (see Figure 5), and depressive score at follow-up ( $\tau^{2}<0.0001,95 \%$-CI $[0.0000 ; 6.8479] ; \mathrm{I}^{2}=38.6 \%, 95 \%$ CI $[0.0 \% ; 77.2 \%], \mathrm{p}=0.16$ (see Figure 6 ).

To explore what causes this between-study heterogeneity when assessing depressive score and to evaluate the robustness of our pooled results, we conducted an outlier and influence analyses (65) using a leave-one-out method (see Supplementary results). Importantly, theses analyses revealed a possible overestimation of the pooled effect size of studies assessing depressive scores. By removing one study (the outlier) (35), the pooled effect of $g=0.73$ is smaller than our initial estimate $g=0.84$, but still within the same orders of magnitude. The heterogeneity $\mathrm{I}^{2}$ also decreased from $42,5 \%$ (95\%-CI 0\%-70\%) to 0\% (95\%-CI 0\%-58\%) (see Figure S2 and Table S3). Our subgroup analyses indicated an influence of the outcome measurement used to evaluate the clinical symptoms (see Table S1 in Supplementary Materials), of the number of sessions (see Table S2) and the number of runs (see Table S3) on the between-study heterogeneity (see Supplementary results).

\subsubsection{Between-group analysis}

The between-group analysis showed a medium effect size at the primary endpoint within 10 studies assessing depressive score improvement $(g=0.46$ 95\% CI [0.75-0.78], $\mathrm{T}=3.36, \mathrm{p}<$ 0.01). A large-effect size was found across 5 studies evaluating anxiety's improvement ( $g=$ $0.9195 \%$ CI [-0.20 2.02], $\mathrm{T}=2.27, \mathrm{p}=0.09)$.

The between-study heterogeneity variance did not reach significant level for the depressive symptom $\left(\tau^{2}<0.000195 \%\right.$-CI [0.0000; 0.5858], $\mathrm{I}^{2}=11 \% 95 \%$-CI [0.0\%; 51.9\%], p = 0.34). However, the between-study heterogeneity was estimated at $\tau^{2}=0.34$ (95\%-CI [0.0388; $7.4947])$, with a heterogeneity factor $\mathrm{I}^{2}$ value of $69 \%(95 \%$-CI $[19.3 \% ; 87.8 \%], \mathrm{p}=0.01)$, 
revealing a significant between-study variance for the anxiety symptom meta-analysis (see Figure 7).

The better understand the between study heterogeneity observed in anxiety's analyses, we conducted an outlier and influence analyses using leave-one-out method. These analyses revealed a possible overestimation of the pooled effect size and an increase of the heterogeneity value. By removing one study (62), the pooled effect decreased from $g=0.91$ to $g=0.57$. The heterogeneity value $\mathrm{I}^{2}$ also decreased from $69 \%$ (95\%-CI [19.3\%; 87.8\%]), to $24 \%$ (95\%-CI [0.0\%; 88.3\%]) (see Figure S3 and Table S7). Our subgroup analyses indicated an influence of the outcome measurement used in one study (62) which tend to overestimate the effect size of between-group analyses assessing anxiety symptoms. This is consistent with our leave-one-out analyses. 


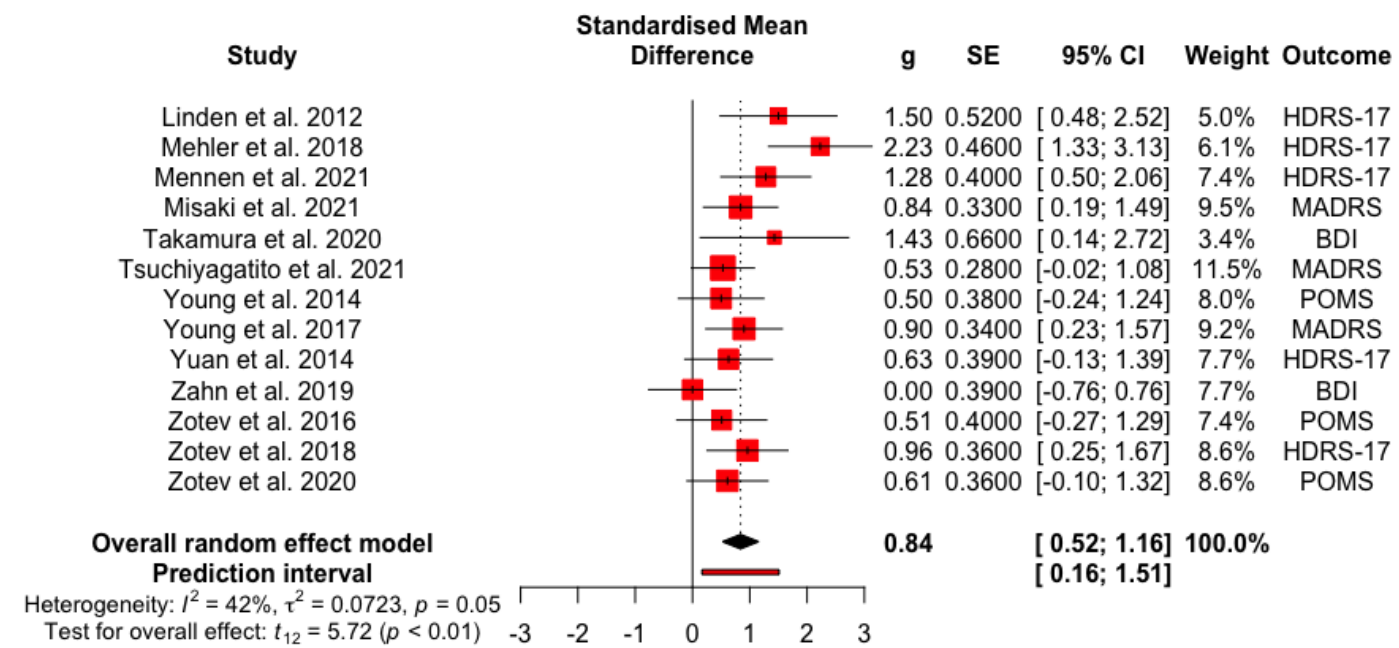
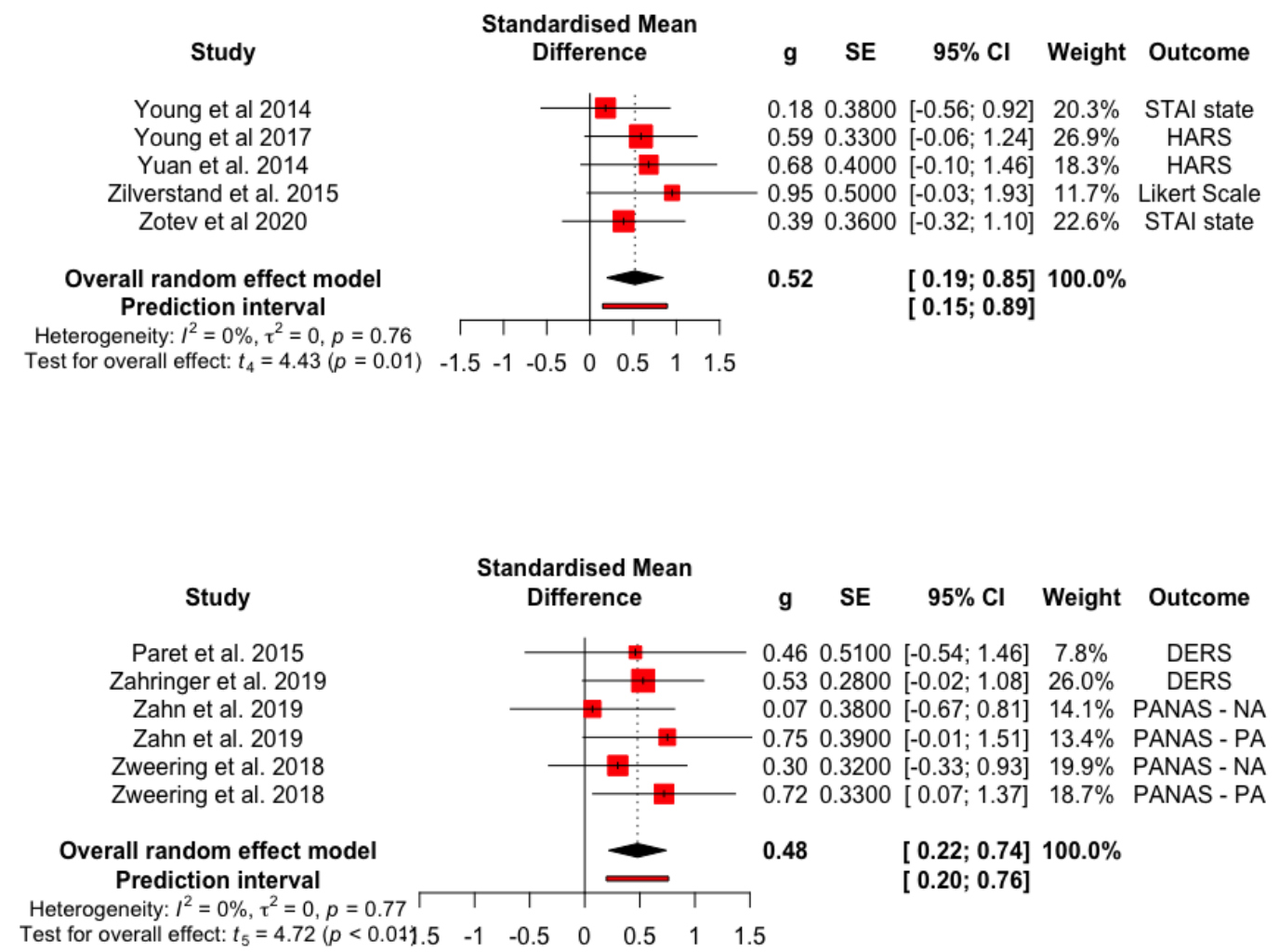

Figure 5. Forest plot with overall effect of NF training after the primary endpoint on depressive score (top panel), anxiety symptoms (middle panel) and emotion regulation (bottom panel) symptoms. $\mathrm{CI}=$ confidence interval, $\mathrm{g}=$ Hedge's effect size, $\mathrm{SE}=$ standard error 


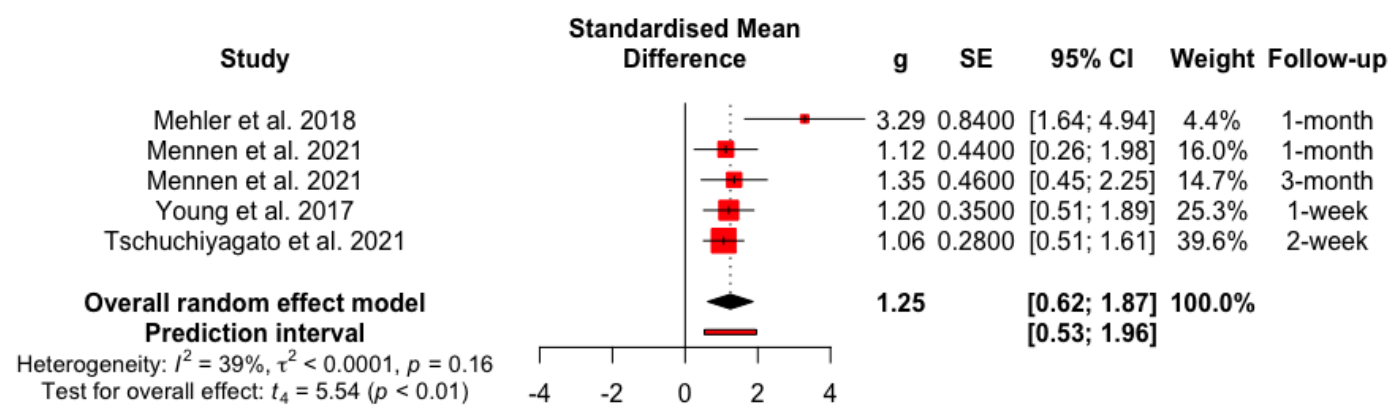

Figure 6. Forest plot with overall effect of NF training at follow-up on depressive score. $\mathrm{CI}=$ confidence interval, FU = follow-up, g = Hedge's effect size, $\mathrm{SE}=$ standard error 


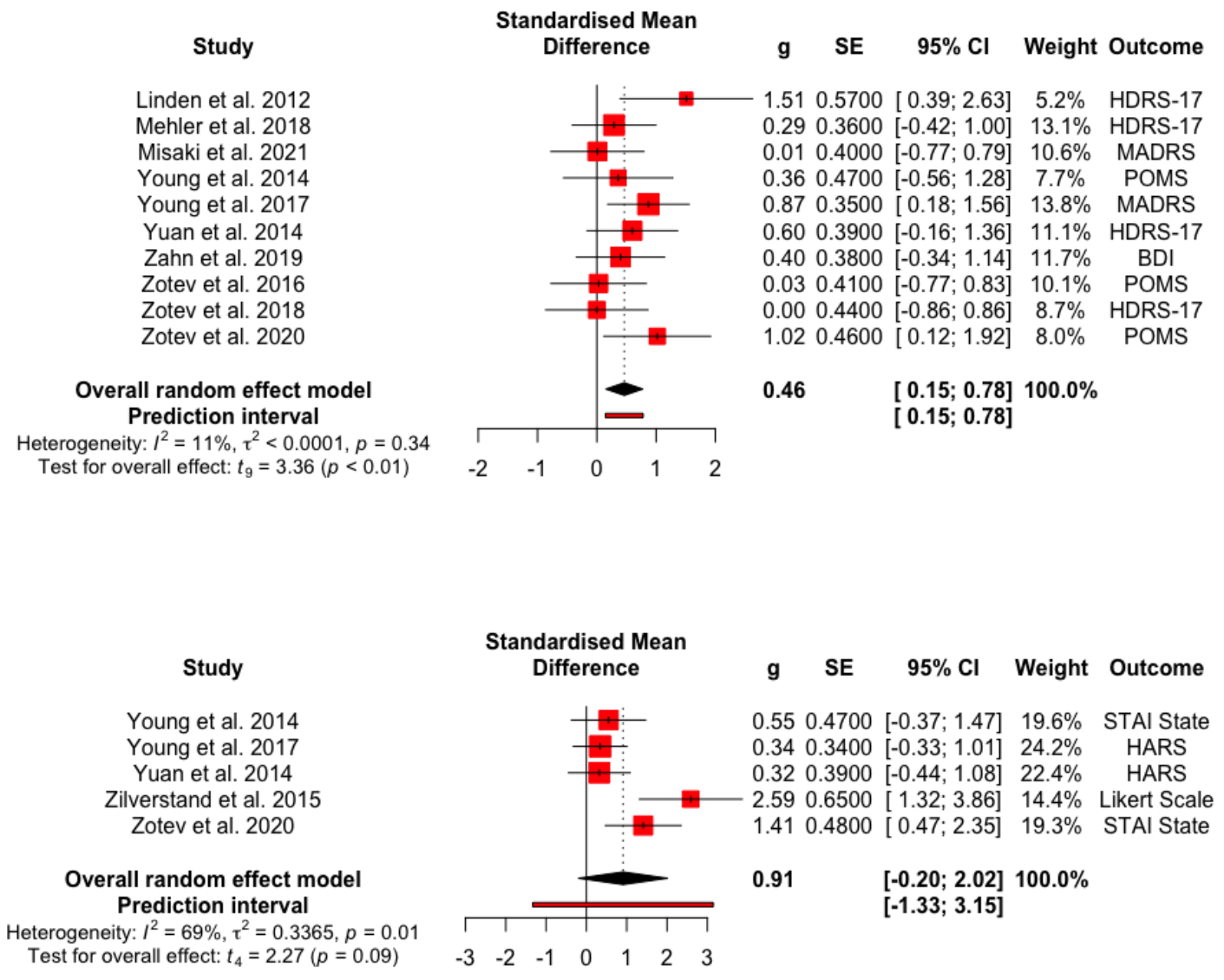

Figure 7. Forest plot of between-group analysis with overall effect of NF training at primary endpoint on depressive score (top) and on anxiety score (bottom). $\mathrm{CI}=$ confidence interval, $\mathrm{g}$ $=$ Hedge's effect size, $\mathrm{SE}=$ standard error 


\section{Discussion}

Since the emergence of RT-fMRI-NF, the interest in its use is still growing in the scientific community. This technique allows participants to self-regulate the activity of region(s) in their brain, through real-time feedback. As this technique can be used in combination with pharmaceutical treatments, many studies attempt to integrate RT-fMRI-NF in the health care pathway of patients with psychiatric conditions. Because the clinical effectiveness is not clearly established, we conducted a systematic review and meta-analysis to evaluate the efficacy of RT-fMRI-NF in the improvement of clinical symptoms in various psychiatric disorders. Thirty studies assessed the effectiveness of RT-fMRI-NF on the improvement of psychiatric clinical symptoms. Out of the 31 studies, 20 reported significant clinical improvement in the experimental group after NF training with eight of them with a sustained improvement at follow-up, 8 slight symptoms improvement in the experimental group after the training while two reported also a sustained improvement at follow-up, one reported improvement in both the experimental and the control group, one reported sustained improvement at follow-up (post-NF training results not available) and one reported no difference in symptoms enhancement in the experimental group after the NF-training. We found only two double-blind randomized controlled trials that showed clinical symptoms improvement in mood disorders after the training. In general, studies on mood disorders showed a large effect on depressive symptoms when targeting the amygdala with a greater effect in the experimental group compared to the control group after the training. The variety of paradigms and methodologies used is wide and the heterogeneity of the results very high.

The meta-analysis of RT-fMRI-NF studies pointed a significant clinical improvement in depressive, anxiety symptoms and emotion regulation in the experimental groups between baseline and the end of the NF training and showed a clinical improvement in anxiety symptoms in the experimental group compared with sham control groups. This suggests that the clinical improvement following NF training cannot be attributed simply to the general processes involved in the training such as expectations, participant's exposure or reward processing (discussed below) (66). The clinical improvement in depressive score is maintained beyond the NF training with a large effect size. The present meta-analyses should be interpreted with caution since there is heterogeneity in effect sizes between studies, particularly in those assessing depressive score. This is indicated by the $\mathrm{I}^{2}$ parameter and $\tau^{2}(33)$, illustrating that a large proportion of the total variation in the described sample remains to be explained. 
Interestingly, we tested the influence of certain design parameters (i.e., the outcome measure, the number of session and the number of run). We found a statistical significance, indicating that the parameters alone could explain the variability in modulation effect size. This suggests that heterogeneity across studies may arise from several variables, and perhaps from an interaction between design choices that will be discussed in the subsequent discussion.

For successful clinical trials in the neurofeedback studies, the choice of the control condition is a critical challenge to prove the efficacy of the technique, and to dissociate the changes relying on the neurofeedback training itself from other factors (e.g., mental strategy, the attention, the motivation) that comes through participation in neurofeedback training $(67,68)$. The design of the study can either involve a passive control group (e.g., continuing the treatment as usual (TAU) vs. TAU and neurofeedback training) (59), or researchers can choose to employ an active control group (e.g., performing the same task as the experimental group but receiving the signal from another participant in the experimental group) (69). There is no consensus yet as to which control conditions is the most optimal $(66,70)$. Some studies have shown that participants who believe they are receiving the true feedback (even if they did not) show significant changes in attention (53) and depressive symptoms (35). This highlights the importance of conducting rigorous randomized double-blind placebo-controlled NF studies, which is considered as the gold standard in clinical trials. However, many studies identified in our systematic review lack adequate control. Only 22 studies out of 31 reviewed studies included a control group. Eleven were included in the meta-analysis. Several studies used as a control condition, a region not involved in the targeted cognitive process (i.e., sham feedback; 12 out of 22 controlled studies). As an example, Young et al. (2014) used the signal from the intraparietal sulcus as sham feedback for the control group and from the amygdala for the experimental group. They showed a significant increase in happiness in depressed patients in the experimental group. This enables to control for the level of motivation and belief of those receiving the real NF $(66,71)$, but it is difficult to identify regions not involved in a cognitive process and participants may become discouraged because the visual feedback may not follow their attempts to achieve regulation. Other studies decided not to provide feedback on brain activity to the control group but to give them the same cognitive task as the experimental group $(55,57,62)$, which allowed the authors to prove that the observed effects were not due to the participants' exposure to the training, but to the cognitive consequences induced by the feedback on their brain activity. We can then conclude that, ideally, both a sham-control group and a nofeedback group should be used in clinical trials (72). However, the inclusion of two control 
conditions would be considerably expensive and time consuming (66,71). Sorger et al. (2019) argue that the type of control condition depends on the purpose of the neurofeedback study. To determine clinical efficacy, sham neurofeedback groups might be more appropriate because participants in both experimental and control groups are engaged in the same experimental procedure.

As the gold standard in clinical trials, double-blinded trials allow to prevent behavioral changes resulting from NF training to be attributed to experimental biases, such as the involuntary transmission of hypotheses or knowledge of which group the participants is assigned to, which may influence the participant's and investigator's motivation (73). In addition, randomization is an important aspect of the control of the experimental bias, to allow an equivalence and a fair comparison between the experimental and the control groups. Such well-controlled double-blind randomized placebo-controlled clinical trials in NF-fMRI studies are so far quite rare $(71,74)$. Only two out of the 22 controlled-studies reviewed used doubleblind randomized controlled procedures $(38,40)$. Therefore, more rigorous, double-blind RCTs are needed in order to prove the clinical efficacy of RT-fMRI-NF training in the treatment of psychiatric disorders $(72,75)$.

The primary outcome for all studies was to evaluate the progression of the symptomatology after the NF training. In order to demonstrate the clinical efficacy of the RT-fMRI-NF training, studies have to show (1) an additional improvement in the experimental group in comparison to the control group (i.e. between-group comparisons) ; (2) the transferability of RT-fMRI-NF to situations where the feedback is absent (i.e. during the transfer run) and (3) the sustainable effect over time as measured by follow-up visits (71). Between-group comparisons after the training and ideally an interaction between Groups (experimental vs. control) and Time (pre vs. post training) are required to conclude as to the efficacy of the NF training vs. placebo or retest effect. Young et al. (2017) provided a good example. They found that left amygdala neurofeedback training reduced depressive symptoms right after the training and at 1-week follow up with a transfer effect post-NF training. The optimal duration of the follow-up is not yet well established. Some studies reported a sustained improvement after RT-fMRI-NF training for a month $(35,36,53,56,59,61,62)$, while others only after one week $(38,43,44,47)$. Despite the importance of these measures, only 10 studies out of the 30 reviewed collected and reported follow-up data. This leads to a reduction of the clinical relevance of this technique and may lead to an underestimation of the size of the NF effect. We would recommend future studies 
to systematically assess the evolution of the symptoms post-NF training for at least three months after the training.

The efficacy of neurofeedback can be dependent on the number of runs and sessions of NF training. Indeed, the number and the length of each training session and runs varies considerably across different studies. We reported a high variability in the number of sessions in studies included in this systematic review (range $=1-12$ ). The number of sessions chosen in each study seems somewhat arbitrary as the ideal number of sessions for optimal training response is not yet well established (70,71). Young et al. (2017) reported lower depressive scores after two NF training sessions (with three runs each). Similarly, Bauer et al. (2020) showed an improvement in auditory hallucinations after two NF training sessions (with four runs each). As suggested by Zahn et al. (2019), the ability of a single session of RT-fMRI-NF training to produce lasting changes in neural processes and the related symptomatology appears to be somewhat lacking in credibility. Indeed, they did not report score differences in depressive symptoms in patients with remitted MDD whilst retrieving guilt and indignation/anger-related autobiographical memories, after a single NF training session by targeting the ATL-SCC connectivity. Further research needs to be done to identify the optimal number of sessions and runs required in RTfMRI-NF experiments for clinical efficacy (72) by considering contextual and individual factors that can affect the optimal training (motivation, the time of day when participants are tested, age, participant sleep time, physical condition, menstrual cycle).

One of the most challenging issues encountered in RT-fMRI-NF research is undoubtedly the choice of target region(s). The question is whether fMRI-based NF should focus on localized activity (i.e., BOLD response) in a target specific region (defined a priori with standard atlases or through a subject specific localizer), or rather on network related parameters. If only one target region is chosen to be modulated by NF training, it is important to ask whether the primary purpose of the training is to regulate the activation of a disrupted region (e.g., amygdala in emotion regulation $(39,42,52,61)$; or the prefrontal cortex in addictions $(57,58)$ ). Most studies reviewed here (26 out of the 31 ) used a single-ROI approach. The amygdala, the medial and lateral prefrontal regions, including the ACC and limbic regions are the regions most used as ROIs. These regions are relevant targets for RT-fMRI-NF studies because of their role in self-regulation, emotion regulation and reward processes. Salience network areas, such as the insula, were used in some studies because of the role in the regulation of emotion (fear, sadness). The ROI-based approach is based on the hypothesis that specific regions might be 
critical in the pathophysiology in a given disorder or symptom $(72,76)$ without considering that cerebral regions are widely interconnected and a specific region could be considered as a hub. A growing number of RT-fMRI-NF studies target functional connections rather than a singleROI (72). There is some evidence that connectivity-based signals are more effective than ROIbased approaches. In Kim et al. (2015), researchers showed that the connectivity feedback was more efficient than the ROI feedback in cigarette craving regulation in healthy individuals (26). In contrast to studies using a single ROI-based approach, five studies here reviewed adopted a connectivity-based approach $(36,40,44,54,59)$. It consists of returning functional connectivity measurements, i.e., the measure synchronization or desynchronization of brain activity between different brain regions (71,72). For example, Ramot et al. (2017) used a connectivity-based approach to target the connectivity between the STS and the SCC in patients with ASD. They showed an increase in STS-SCC connectivity during resting-state and showed a reduction in autistic traits in the experimental group after the training.

The selection of specific regions is very important, especially in children and adolescents. Indeed, one could ask whether it is more adequate to train a young patient to regulate brain regions involved in a cognitive function at a specific developmental state or whether they should be trained to directly regulate the brain networks that support that ability in a mature adult brain (68). Only one study in this review trained adolescents and adults with ASD to regulate the STS-SCC functional connectivity (54). However, they did not consider the age of the participants and the putative cerebral anatomical differences. Indeed, it is important for future RT-fMRI-NF to consider that during brain development, cognitive functions are not always supported by the same brain networks as in adulthood (68).

The development of multivariate approaches or "multivariate pattern analysis" (MVPA) in the neuroimaging field also offers promising applications for neurofeedback training. Classifier-based MVPA aims to classify brain activity associated with the to-be-discriminated cognitive states and then provide feedback based on proximity to the desired brain state $(77,78)$. Methods such as Decoded Neurofeedback (or DecNef) aim at discovering a pattern of brain activity that might be related to different brain states, and to target these patterns in NF training (79). The purpose of this technique is to train participants to regulate ongoing brain activity related to a specific behavior $(66,73)$. The advantage of this procedure is that it incorporates data from the entire brain (multivariate per se) and compensatory processes outside the expected ROIs or networks (66). To date, only one study has been conducted using DecNef to reduce 
subsyndromal phobia to spiders, with promising results (80). DecNef method seems to be highly relevant to target the complexity of the neuropathophysiology of psychiatric disorders. We suggest that future studies should consider the growing understanding of the importance of functional connectivity and multiple brain regions involved in complex behaviors and patients' symptomatology.

Another source of variability in the studies referenced in the current review concerns the evaluation of the symptoms. Different scales can be used to evaluate the intensity of a given symptom. For example, to assess the intensity of the depressive symptoms, the MADRS and the HDRS are the most common clinical scales used. Although both scales assess the severity of depression, they differ according to the number of items (10 for the MADRS and 21 for the HDRS) and their scoring (i.e., all items are used to measure depression severity with the MADRS, while with the HDRS only the first 17 items are used). This heterogeneity in clinical scales used makes meta-analyses either difficult or impossible to perform. In our meta-analyses, the subgroup analyses showed a statistical significance for the heterogeneity in studies using HDRS-17 in studies assessing depressive score. Standardization of the clinical rating scales for each symptom could help bypass these difficulties.

In this review, we did not include EEG-NF studies. However, EEG and fMRI are two complementary techniques. EEG has a high temporal resolution. However, its spatial resolution is limited by the number of electrodes. Importantly, EEG does not allow a good source localization for deep brain structures. In contrast, fMRI has a higher spatial resolution and allows a whole-brain exploration. However, its temporal resolution is constrained by the delay of the hemodynamic response. The major motivation for the combination of both techniques is the possibility of linking the precise anatomical localization and precise temporal evolution of brain activation signals for real-time feedback (12,72,81). Machine learning algorithms are a great tool to help the reconstruction of the EEG signal source to have a fine temporal resolution of a deep brain area. In Zotev et al. (2014), participants underwent a RT-fMRI-EEG-NF protocol in depression. The EEG-NF was used for regulation of frontal asymmetry in the highbeta band $(21-30 \mathrm{~Hz})$ and the fMRI-NF was used for the regulation of the activity of the left amygdala. They applied RT-fMRI-EEG-NF to emotional self-regulation training in healthy subjects performing a positive emotion induction task based on the retrieval of happy autobiographical memories. Participants were able to regulate both their BOLD fMRI activation in the left amygdala and frontal power asymmetry in the high-beta band. In this 
review, three studies used RT-fMRI-EEG-NF in major depressive disorders $(42,63)$ and in PTSD (41). Zotev et al. (2016) showed an improvement in depression scores after the RTfMRI-EEG-NF training. They used a simultaneous EEG recording during RT-fMRI-NF paradigm, allowing to identify electrophysiological correlates of the RT-fMRI-NF training (63). With this paradigm, EEG correlates of fMRI-NF could be used as potential targets for EEG-NF or EEG-fMRI-NF for more efficient and/or more portable neurotherapies. Keynan et al., (2019) reported promising results with an RT-fMRI-EEG-NF study in alexithymia by targeting the amygdala activity in healthy participants. Although this technique is promising, there is very few RT-fMRI-EEG-NF research applied to psychiatric disorders. Indeed, it is an expensive and complicated technique to set up because of the EEG/MRI compatibility issues and the heaviness of the protocol for the participants. Further research must be done to overcome those technical issues and lead to advances in the non-pharmacological treatment of psychiatric pathologies. 


\section{Conclusion}

RT-fMRI-NF provides patients to access, beyond mental states, to their own brain activity. The possibilities offered by this technique are multiple for the management of certain clinical psychiatric symptoms. Our review showed that, indeed, many studies found significant clinical improvements after NF training, especially in mood disorders. Although the use of RT-fMRI$\mathrm{NF}$ in psychiatry is appealing, the level of evidence given by recent clinical trials remains moderate. Most studies face methodological issues both in the design and the report of the results of the performed trials. Considered as the gold-standard in clinical research, conducting double-blind randomized-controlled trials is still a major challenge for future RT-fMRI-NF studies. Innovative techniques, such as NF experiments based on functional connectivity or using a multivariate approach, offer new perspectives that could help to target the complex pathophysiology of psychiatric disorders and to ultimately relieve symptoms of patients suffering from psychiatric disorders. 


\section{Authors contribution}

PP conducted the review and wrote the first draft of the manuscript along with PF. PF and JH conceptualized this review. All authors contributed to and have approved the final manuscript.

\section{Acknowledgements}

This research is supported by the "Fondation FondaMental", "Fondation FondaMental Suisse", and the Programme Hospitalier de Recherche Clinique from the French Ministry for Health (PHRC-N 2019 “Neurofeed-BD”).

\section{Conflict of Interest}

All authors declare no conflict of interest. 


\section{References}

1. Patel V, Saxena S, Lund C, Thornicroft G, Baingana F, Bolton P, Chisholm D, Collins PY, Cooper JL, Eaton J, et al. The Lancet Commission on global mental health and sustainable development. The Lancet (2018) 392:1553-1598. doi: 10.1016/S01406736(18)31612-X

2. Williams NR, Okun MS. Deep brain stimulation (DBS) at the interface of neurology and psychiatry. J Clin Invest (2013) 123:4546-4556. doi: 10.1172/JCI68341

3. Demeulemeester M, Amad A, Bubrovszky M, Pins D, Thomas P, Jardri R. What Is the Real Effect of 1-Hz Repetitive Transcranial Magnetic Stimulation on Hallucinations? Controlling for Publication Bias in Neuromodulation Trials. Biological Psychiatry (2012) 71:e15-e16. doi: 10.1016/j.biopsych.2011.10.010

4. Agarwal SM, Shivakumar V, Bose A, Subramaniam A, Nawani H, Chhabra H, V S, Kalmady, C J, Narayanaswamy, et al. Transcranial Direct Current Stimulation in Schizophrenia. Clin Psychopharmacol Neurosci (2013) 11:118-125. doi: 10.9758/cpn.2013.11.3.118

5. Sitaram R, Ros T, Stoeckel L, Haller S, Scharnowski F, Lewis-Peacock J, Weiskopf N, Blefari ML, Rana M, Oblak E, et al. Closed-loop brain training: the science of neurofeedback. Nat Rev Neurosci (2017) 18:86-100. doi: 10.1038/nrn.2016.164 6. Heinrich H, Gevensleben H, Freisleder FJ, Moll GH, Rothenberger A. Training of slow cortical potentials in attention-deficit/hyperactivity disorder: evidence for positive behavioral and neurophysiological effects. Biological Psychiatry (2004) 55:772-775. doi: 10.1016/j.biopsych.2003.11.013

7. Fuchs T, Birbaumer N, Lutzenberger W, Gruzelier JH, Kaiser J. Neurofeedback Treatment for Attention-Deficit/ Hyperactivity Disorder in Children: A Comparison With Methylphenidate. Applied Psychophysiology and Biofeedback (2003) 28:1-12. doi: 10.1023/A:1022353731579

8. Lubar JO, Lubar JF. Electroencephalographic biofeedback of SMR and beta for treatment of attention deficit disorders in a clinical setting. Biofeedback and Self-Regulation (1984) 9:1-23. doi: 10.1007/BF00998842

9. Birbaumer N, Ruiz S, Sitaram R. Learned regulation of brain metabolism. Trends in Cognitive Sciences (2013) 17:295-302. doi: 10.1016/j.tics.2013.04.009

10. Ogawa S, Lee TM, Kay AR, Tank DW. Brain magnetic resonance imaging with contrast dependent on blood oxygenation. Proceedings of the National Academy of Sciences (1990) 87:9868-9872. doi: 10.1073/pnas.87.24.9868

11. Cox RW, Jesmanowicz A, Hyde JS. Real-Time Functional Magnetic Resonance Imaging. Magn Reson Med (1995) 33:230-236. doi: 10.1002/mrm.1910330213

12. Weiskopf N. Real-time fMRI and its application to neurofeedback. NeuroImage (2012) 62:682-692. doi: 10.1016/j.neuroimage.2011.10.009

13. Weiskopf N, Veit R, Erb M, Mathiak K, Grodd W, Goebel R, Birbaumer N. Physiological self-regulation of regional brain activity using real-time functional magnetic resonance imaging (fMRI): methodology and exemplary data. NeuroImage (2003) 19:577586. doi: 10.1016/S1053-8119(03)00145-9

14. deCharms RC, Maeda F, Glover GH, Ludlow D, Pauly JM, Soneji D, Gabrieli JDE, Mackey SC. Control over brain activation and pain learned by using real-time functional MRI. Proceedings of the National Academy of Sciences (2005) 102:18626-18631. doi: 10.1073/pnas.0505210102

15. Haller S, Birbaumer N, Veit R. Real-time fMRI feedback training may improve chronic tinnitus. Eur Radiol (2010) 20:696-703. doi: 10.1007/s00330-009-1595-Z 
16. Fovet T, Jardri R, Linden D. Current Issues in the Use of fMRI-Based Neurofeedback to Relieve Psychiatric Symptoms. CPD (2015) 21:3384-3394. doi:

$10.2174 / 1381612821666150619092540$

17. Dudek E, Dodell-Feder D. The efficacy of real-time functional magnetic resonance imaging neurofeedback for psychiatric illness: A meta-analysis of brain and behavioral outcomes. Neuroscience \& Biobehavioral Reviews (2021) 121:291-306. doi:

10.1016/j.neubiorev.2020.12.020

18. Trambaiolli LR, Kohl SH, Linden DEJ, Mehler DMA. Neurofeedback training in major depressive disorder: A systematic review of clinical efficacy, study quality and reporting practices. Neuroscience \& Biobehavioral Reviews (2021) 125:33-56. doi: 10.1016/j.neubiorev.2021.02.015

19. Liberati A, Altman DG, Tetzlaff J, Mulrow C, Gotzsche PC, Ioannidis JPA, Clarke M, Devereaux PJ, Kleijnen J, Moher D. The PRISMA statement for reporting systematic reviews and meta-analyses of studies that evaluate healthcare interventions: explanation and elaboration. BMJ (2009) 339:b2700-b2700. doi: 10.1136/bmj.b2700

20. Association AP, Staff APA, DSM-IV APATF on. Diagnostic and Statistical Manual of Mental Disorders, Fourth Edition: DSM-IV-TRß. American Psychiatric Association (2000). 994 p.

21. American Psychiatric Association, American Psychiatric Association eds. Diagnostic and statistical manual of mental disorders: DSM-5. 5th ed. Washington, D.C: American Psychiatric Association (2013). 947 p.

22. World Health Organization ed. The ICD-10 classification of mental and behavioural disorders: clinical descriptions and diagnostic guidelines. Geneva: World Health Organization (1992). 362 p.

23. Lecrubier Y, Sheehan DV, Weiller E, Amorim P, Bonora I, Sheehan KH, Janavs J, Dunbar GC. Mini International Neuropsychiatric Interview. (2013) doi: 10.1037/t18597-000 24. Gorgens KA. "Structured Clinical Interview For DSM-IV (SCID-I/SCID-II).," In: Kreutzer JS, DeLuca J, Caplan B, editors. Encyclopedia of Clinical Neuropsychology. New York, NY: Springer New York (2011). p. 2410-2417 doi: 10.1007/978-0-387-79948-3_2011 25. Takamura M, Okamoto Y, Shibasaki C, Yoshino A, Okada G, Ichikawa N, Yamawaki S. Antidepressive effect of left dorsolateral prefrontal cortex neurofeedback in patients with major depressive disorder: A preliminary report. J Affect Disord (2020) 271:224-227. doi: 10.1016/j.jad.2020.03.080

26. Kim D-Y, Yoo S-S, Tegethoff M, Meinlschmidt G, Lee J-H. The Inclusion of Functional Connectivity Information into fMRI-based Neurofeedback Improves Its Efficacy in the Reduction of Cigarette Cravings. Journal of Cognitive Neuroscience (2015) 27:15521572. doi: 10.1162/jocn_a_00802

27. Li X, Hartwell KJ, Borckardt J, Prisciandaro JJ, Saladin ME, Morgan PS, Johnson KA, LeMatty T, Brady KT, George MS. Volitional reduction of anterior cingulate cortex activity produces decreased cue craving in smoking cessation: a preliminary real-time fMRI study: Nicotine and real-time fMRI. Addiction Biology (2013) 18:739-748. doi:

10.1111/j.1369-1600.2012.00449.x

28. Lüdecke D. esc: Effect Size Computation for Meta Analysis. Zenodo (2018). doi: 10.5281/zenodo.1249218

29. Cuijpers P. Meta-analysis in mental health: a practical guide. (2016).

30. Higgins J, Thomas J, Chandler J, Cumpston M, Li T, Page M, Welch V (editors). Cochrane Handbook for Systematic Reviews of Interventions version 6.2 (updated February 2021). (2021). www.training.cochrane.org/handbook

31. Viechtbauer W. Bias and Efficiency of Meta-Analytic Variance Estimators in the Random-Effects Model. Journal of Educational and Behavioral Statistics (2005) 30:261-293. 
doi: $10.3102 / 10769986030003261$

32. Knapp G, Hartung J. Improved tests for a random effects meta-regression with a single covariate. Stat Med (2003) 22:2693-2710. doi: 10.1002/sim.1482

33. Higgins JPT, Thompson SG. Quantifying heterogeneity in a meta-analysis. Stat Med (2002) 21:1539-1558. doi: 10.1002/sim.1186

34. Linden DEJ, Habes I, Johnston SJ, Linden S, Tatineni R, Subramanian L, Sorger B, Healy D, Goebel R. Real-Time Self-Regulation of Emotion Networks in Patients with Depression. PLoS ONE (2012) 7:e38115. doi: 10.1371/journal.pone.0038115

35. Mehler DMA, Sokunbi MO, Habes I, Barawi K, Subramanian L, Range M, Evans J, Hood K, Lührs M, Keedwell P, et al. Targeting the affective brain-a randomized controlled trial of real-time fMRI neurofeedback in patients with depression. Neuropsychopharmacology (2018) 43:2578-2585. doi: 10.1038/s41386-018-0126-5

36. Mennen AC, Turk-Browne NB, Wallace G, Seok D, Jaganjac A, Stock J, deBettencourt MT, Cohen JD, Norman KA, Sheline YI. Cloud-Based Functional Magnetic Resonance Imaging Neurofeedback to Reduce the Negative Attentional Bias in Depression: A Proof-of-Concept Study. Biological Psychiatry: Cognitive Neuroscience and Neuroimaging (2021) 6:490-497. doi: 10.1016/j.bpsc.2020.10.006

37. Young KD, Zotev V, Phillips R, Misaki M, Yuan H, Drevets WC, Bodurka J. RealTime fMRI Neurofeedback Training of Amygdala Activity in Patients with Major Depressive Disorder. PLoS ONE (2014) 9:e88785. doi: 10.1371/journal.pone.0088785

38. Young KD, Siegle GJ, Zotev V, Phillips R, Misaki M, Yuan H, Drevets WC, Bodurka J. Randomized Clinical Trial of Real-Time fMRI Amygdala Neurofeedback for Major Depressive Disorder: Effects on Symptoms and Autobiographical Memory Recall. AJP (2017) 174:748-755. doi: 10.1176/appi.ajp.2017.16060637

39. Yuan H, Young KD, Phillips R, Zotev V, Misaki M, Bodurka J. Resting-State Functional Connectivity Modulation and Sustained Changes After Real-Time Functional Magnetic Resonance Imaging Neurofeedback Training in Depression. Brain Connectivity (2014) 4:690-701. doi: 10.1089/brain.2014.0262

40. Zahn R, Weingartner JH, Basilio R, Bado P, Mattos P, Sato JR, de Oliveira-Souza R, Fontenelle LF, Young AH, Moll J. Blame-rebalance fMRI neurofeedback in major depressive disorder: A randomised proof-of-concept trial. NeuroImage: Clinical (2019) 24:101992. doi: 10.1016/j.nicl.2019.101992

41. Zotev V, Phillips R, Misaki M, Wong CK, Wurfel BE, Krueger F, Feldner M, Bodurka J. Real-time fMRI neurofeedback training of the amygdala activity with simultaneous EEG in veterans with combat-related PTSD. NeuroImage: Clinical (2018) 19:106-121. doi: 10.1016/j.nicl.2018.04.010

42. Zotev V, Mayeli A, Misaki M, Bodurka J. Emotion self-regulation training in major depressive disorder using simultaneous real-time fMRI and EEG neurofeedback. Neuroimage Clin (2020) 27:102331. doi: 10.1016/j.nicl.2020.102331

43. Tsuchiyagaito A, Misaki M, Zoubi OA, Tulsa 1000 Investigators, Paulus M, Bodurka J. Prevent breaking bad: A proof of concept study of rebalancing the brain's rumination circuit with real-time fMRI functional connectivity neurofeedback. Hum Brain Mapp (2020) doi: 10.1002/hbm.25268

44. Bauer CCC, Okano K, Gosh SS, Lee YJ, Melero H, Angeles C de los, Nestor PG, del Re EC, Northoff G, Niznikiewicz MA, et al. Real-time fMRI neurofeedback reduces auditory hallucinations and modulates resting state connectivity of involved brain regions: Part 2:

Default mode network -preliminary evidence. Psychiatry Research (2020) 284:112770. doi: 10.1016/j.psychres.2020.112770

45. Dyck MS, Mathiak KA, Bergert S, Sarkheil P, Koush Y, Alawi EM, Zvyagintsev M, Gaebler AJ, Shergill SS, Mathiak K. Targeting Treatment-Resistant Auditory Verbal 
Hallucinations in Schizophrenia with fMRI-Based Neurofeedback - Exploring Different Cases of Schizophrenia. Front Psychiatry (2016) 7: doi: 10.3389/fpsyt.2016.00037

46. Okano K, Bauer CCC, Ghosh SS, Lee YJ, Melero H, de los Angeles C, Nestor PG, del Re EC, Northoff G, Whitfield-Gabrieli S, et al. Real-time fMRI feedback impacts brain activation, results in auditory hallucinations reduction: Part 1: Superior temporal gyrus Preliminary evidence-. Psychiatry Research (2020) 286:112862. doi:

10.1016/j.psychres.2020.112862

47. Orlov ND, Giampietro V, O’Daly O, Lam S-L, Barker GJ, Rubia K, McGuire P, Shergill SS, Allen P. Real-time fMRI neurofeedback to down-regulate superior temporal gyrus activity in patients with schizophrenia and auditory hallucinations: a proof-of-concept study. Transl Psychiatry (2018) 8:46. doi: 10.1038/s41398-017-0067-5

48. Ruiz S, Lee S, Soekadar SR, Caria A, Veit R, Kircher T, Birbaumer N, Sitaram R. Acquired self-control of insula cortex modulates emotion recognition and brain network connectivity in schizophrenia. Hum Brain Mapp (2013) 34:200-212. doi: 10.1002/hbm.21427 49. Gerin MI, Fichtenholtz H, Roy A, Walsh CJ, Krystal JH, Southwick S, Hampson M. Real-Time fMRI Neurofeedback with War Veterans with Chronic PTSD: A Feasibility Study. Front Psychiatry (2016) 7: doi: 10.3389/fpsyt.2016.00111

50. Nicholson AA, Rabellino D, Densmore M, Frewen PA, Paret C, Kluetsch R, Schmahl C, Théberge J, Neufeld RWJ, McKinnon MC, et al. The neurobiology of emotion regulation in posttraumatic stress disorder: Amygdala downregulation via real-time fMRI neurofeedback. Hum Brain Mapp (2017) 38:541-560. doi: 10.1002/hbm.23402

51. Zweerings J, Pflieger EM, Mathiak KA, Zvyagintsev M, Kacela A, Flatten G, Mathiak K. Impaired Voluntary Control in PTSD: Probing Self-Regulation of the ACC With RealTime fMRI. Front Psychiatry (2018) 9:219. doi: 10.3389/fpsyt.2018.00219

52. Misaki M, Mulyana B, Zotev V, Wurfel BE, Krueger F, Feldner M, Bodurka J. Hippocampal volume recovery with real-time functional MRI amygdala neurofeedback emotional training for posttraumatic stress disorder. Journal of Affective Disorders (2021) 283:229-235. doi: 10.1016/j.jad.2021.01.058

53. Alegria AA, Wulff M, Brinson H, Barker GJ, Norman LJ, Brandeis D, Stahl D, David AS, Taylor E, Giampietro V, et al. Real-time fMRI neurofeedback in adolescents with attention deficit hyperactivity disorder: Real-Time fMRI-NF in Adolescents with ADHD. Hum Brain Mapp (2017) 38:3190-3209. doi: 10.1002/hbm.23584

54. Ramot M, Kimmich S, Gonzalez-Castillo J, Roopchansingh V, Popal H, White E, Gotts SJ, Martin A. Direct modulation of aberrant brain network connectivity through realtime NeuroFeedback. eLife (2017) 6:e28974. doi: 10.7554/eLife.28974

55. Zilverstand A, Sorger B, Slaats-Willemse D, Kan CC, Goebel R, Buitelaar JK. fMRI Neurofeedback Training for Increasing Anterior Cingulate Cortex Activation in Adult Attention Deficit Hyperactivity Disorder. An Exploratory Randomized, Single-Blinded Study. PLoS ONE (2017) 12:e0170795. doi: 10.1371/journal.pone.0170795

56. Direito B, Mouga S, Sayal A, Simões M, Quental H, Bernardino I, Playle R, McNamara R, Linden DE, Oliveira G, et al. Training the social brain: Clinical and neural effects of an 8-week real-time functional magnetic resonance imaging neurofeedback Phase IIa Clinical Trial in Autism. Autism (2021) 25:1746-1760. doi: 10.1177/13623613211002052 57. Hartwell KJ, Hanlon CA, Li X, Borckardt JJ, Canterberry M, Prisciandaro JJ, MoranSanta Maria MM, LeMatty T, George MS, Brady KT. Individualized real-time fMRI neurofeedback to attenuate craving in nicotine-dependent smokers. J Psychiatry Neurosci (2016) 41:48-55. doi: 10.1503/jpn.140200

58. Karch S, Keeser D, Hümmer S, Paolini M, Kirsch V, Karali T, Kupka M, Rauchmann B-S, Chrobok A, Blautzik J, et al. Modulation of Craving Related Brain Responses Using Real-Time fMRI in Patients with Alcohol Use Disorder. PLOS ONE (2015) 10:e0133034. doi: 
10.1371/journal.pone.0133034

59. Subramanian L, Skottnik L, Cox WM, Lührs M, McNamara R, Hood K, Watson G, Whittaker JR, Williams AN, Sakhuja R, et al. Neurofeedback Training versus Treatment-asUsual for Alcohol Dependence: Results of an Early-Phase Randomized Controlled Trial and Neuroimaging Correlates. Eur Addict Res (2021)1-14. doi: 10.1159/000513448

60. Paret C, Kluetsch R, Zaehringer J, Ruf M, Demirakca T, Bohus M, Ende G, Schmahl C. Alterations of amygdala-prefrontal connectivity with real-time fMRI neurofeedback in BPD patients. Social Cognitive and Affective Neuroscience (2016) 11:952-960. doi: 10.1093/scan/nsw016

61. Zaehringer J, Ende G, Santangelo P, Kleindienst N, Ruf M, Bertsch K, Bohus M, Schmahl C, Paret C. Improved emotion regulation after neurofeedback: A single-arm trial in patients with borderline personality disorder. NeuroImage: Clinical (2019) 24:102032. doi: 10.1016/j.nicl.2019.102032

62. Zilverstand A, Sorger B, Sarkheil P, Goebel R. fMRI neurofeedback facilitates anxiety regulation in females with spider phobia. Front Behav Neurosci (2015) 9: doi: 10.3389/fnbeh.2015.00148

63. Zotev V, Yuan H, Misaki M, Phillips R, Young KD, Feldner MT, Bodurka J. Correlation between amygdala BOLD activity and frontal EEG asymmetry during real-time fMRI neurofeedback training in patients with depression. NeuroImage: Clinical (2016) 11:224-238. doi: 10.1016/j.nicl.2016.02.003

64. Subramanian L, Hindle JV, Johnston S, Roberts MV, Husain M, Goebel R, Linden D. Real-time functional magnetic resonance imaging neurofeedback for treatment of Parkinson's disease. J Neurosci (2011) 31:16309-16317. doi: 10.1523/JNEUROSCI.3498-11.2011 65. Viechtbauer W, Cheung MW-L. Outlier and influence diagnostics for meta-analysis. Res Synth Methods (2010) 1:112-125. doi: 10.1002/jrsm.11

66. Sorger B, Scharnowski F, Linden DEJ, Hampson M, Young KD. Control freaks: Towards optimal selection of control conditions for fMRI neurofeedback studies. NeuroImage (2019) 186:256-265. doi: 10.1016/j.neuroimage.2018.11.004

67. Thibault RT, Lifshitz M, Raz A. The self-regulating brain and neurofeedback: Experimental science and clinical promise. Cortex (2016) 74:247-261. doi: 10.1016/j.cortex.2015.10.024

68. Paret C, Goldway N, Zich C, Keynan JN, Hendler T, Linden D, Cohen Kadosh K. Current progress in real-time functional magnetic resonance-based neurofeedback: Methodological challenges and achievements. Neuroimage (2019) 202:116107. doi: 10.1016/j.neuroimage.2019.116107

69. Hamilton JP, Glover GH, Bagarinao E, Chang C, Mackey S, Sacchet MD, Gotlib IH. Effects of salience-network-node neurofeedback training on affective biases in major depressive disorder. Psychiatry Research: Neuroimaging (2016) 249:91-96. doi: 10.1016/j.pscychresns.2016.01.016

70. Ros T, Enriquez-Geppert S, Zotev V, Young KD, Wood G, Whitfield-Gabrieli S, Wan F, Vuilleumier P, Vialatte F, Sulzer JS, et al. Consensus on the reporting and experimental design of clinical and cognitive-behavioural neurofeedback studies (CRED-nf checklist). (2020)12.

71. Thibault RT, MacPherson A, Lifshitz M, Roth RR, Raz A. Neurofeedback with fMRI: A critical systematic review. NeuroImage (2018) 172:786-807. doi:

10.1016/j.neuroimage.2017.12.071

72. Fede SJ, Dean SF, Manuweera T, Momenan R. A Guide to Literature Informed Decisions in the Design of Real Time fMRI Neurofeedback Studies: A Systematic Review. Front Hum Neurosci (2020) 14:60. doi: 10.3389/fnhum.2020.00060

73. Shibata K, Lisi G, Cortese A, Watanabe T, Sasaki Y, Kawato M. Toward a 
comprehensive understanding of the neural mechanisms of decoded neurofeedback.

NeuroImage (2019) 188:539-556. doi: 10.1016/j.neuroimage.2018.12.022

74. Linhartová P, Látalová A, Kóša B, Kašpárek T, Schmahl C, Paret C. fMRI neurofeedback in emotion regulation: A literature review. NeuroImage (2019) 193:75-92. doi: 10.1016/j.neuroimage.2019.03.011

75. Schabus M, Griessenberger H, Gnjezda M-T, Heib DPJ, Wislowska M, Hoedlmoser $\mathrm{K}$. Better than sham? A double-blind placebo-controlled neurofeedback study in primary insomnia. Brain (2017) 140:1041-1052. doi: 10.1093/brain/awx011

76. Menon V. Large-scale brain networks and psychopathology: a unifying triple network model. Trends in Cognitive Sciences (2011) 15:483-506. doi: 10.1016/j.tics.2011.08.003

77. Haxby JV. Multivariate pattern analysis of fMRI: The early beginnings. NeuroImage (2012) 62:852-855. doi: 10.1016/j.neuroimage.2012.03.016

78. Lewis-Peacock JA, Norman KA. Multi-Voxel Pattern Analysis of fMRI Data.22.

79. Shibata K, Watanabe T, Sasaki Y, Kawato M. Perceptual Learning Incepted by Decoded fMRI Neurofeedback Without Stimulus Presentation. Science (2011) 334:14131415. doi: 10.1126/science. 1212003

80. Taschereau-Dumouchel V, Cortese A, Chiba T, Knotts JD, Kawato M, Lau H.

Towards an unconscious neural reinforcement intervention for common fears. Proc Natl Acad Sci USA (2018) 115:3470-3475. doi: 10.1073/pnas.1721572115

81. Mulert C, Lemieux L eds. EEG - $f M R I$. Berlin, Heidelberg: Springer Berlin Heidelberg (2010). doi: 10.1007/978-3-540-87919-0

82. Keynan JN, Cohen A, Jackont G, Green N, Goldway N, Davidov A, Meir-Hasson Y, Raz G, Intrator N, Fruchter E, et al. Electrical fingerprint of the amygdala guides neurofeedback training for stress resilience. Nat Hum Behav (2019) 3:63-73. doi: 10.1038/s41562-018-0484-3 
Table 1. Overview of the reviewed studies

\begin{tabular}{|c|c|c|c|c|c|c|c|c|c|c|}
\hline Disorder & Study & Population & $\begin{array}{l}\text { Concomitant Treatment } \\
\text { (EG/CG) }\end{array}$ & $\begin{array}{l}\text { Training target in } \\
\text { experimental group } \\
\text { ( } \mathrm{N} \text { subjects in final } \\
\text { sample) }\end{array}$ & $\begin{array}{l}\text { Training target in } \\
\text { control group (N } \\
\text { subjects in final } \\
\text { sample) }\end{array}$ & $\begin{array}{l}\text { Clinical } \\
\text { outcome } \\
\text { measures }\end{array}$ & $\begin{array}{l}\text { NF training } \\
\text { session number } \\
\text { / runs number }\end{array}$ & $\begin{array}{l}\text { Transfer } \\
\text { run }\end{array}$ & $\begin{array}{l}\text { Follow-up } \\
\text { (duration/ N } \\
\text { sujets) }\end{array}$ & Feedback (type / task) \\
\hline \multirow[t]{2}{*}{ ADHD } & $\begin{array}{l}\text { Alegria et al. } \\
2017\end{array}$ & Adolescents & Psychostimulant (15 / 9) & $\uparrow$ right IFG $(N=18)$ & $\begin{array}{l}\text { Active control group (N } \\
=13) \text { : feedback from } \\
\text { an unrelated control } \\
\text { region (PHG) }\end{array}$ & ADHD - RS & $\begin{array}{l}\text { Nsession }=4 / \\
\text { Nruns }=3-4\end{array}$ & Yes & $\begin{array}{l}\text { Yes }(11 \\
\text { months } / \mathrm{EG}= \\
13, \mathrm{CG}=11)\end{array}$ & $\begin{array}{l}\text { Continuous / Mental } \\
\text { imagery }\end{array}$ \\
\hline & $\begin{array}{l}\text { Zilverstand et } \\
\text { al. } 2017\end{array}$ & Adult & Psychostimulant (3 / 3) & $\uparrow$ dorsal ACC $(\mathrm{N}=7)$ & $\begin{array}{l}\text { Active control group: ( } \\
\mathrm{N}=6 \text { ): no continuous } \\
\text { feedback from ACC }\end{array}$ & ADHD-RS & $\begin{array}{l}\text { Nsession }=4 / \\
\text { Nruns }=3\end{array}$ & Yes & No & $\begin{array}{l}\text { Continuous only for } \\
\text { EG / Mental } \\
\text { calculation }\end{array}$ \\
\hline Anxiety & $\begin{array}{l}\text { Zilverstand et } \\
\text { al. } 2015\end{array}$ & Adult & No & $\begin{array}{l}\uparrow \text { DLPFC }+\downarrow \text { insula } \\
(N=9)\end{array}$ & $\begin{array}{l}\text { Active control group ( } \mathrm{N} \\
\text { =9): different strategy } \\
\text { (reappraisal strategy in } \\
\text { EG vs strategy based on } \\
\text { intuition in CG) }\end{array}$ & $\begin{array}{l}\text { Likert scale + } \\
\mathrm{SBQ}+\mathrm{FSQ}\end{array}$ & $\begin{array}{l}\text { Nsession }=1 / \\
\text { Nruns }=4\end{array}$ & No & $\begin{array}{l}\text { Yes ( } 2 \text { weeks }+ \\
3 \text { months) }\end{array}$ & $\begin{array}{l}\text { Intermittent / Anxiety } \\
\text { provocation }\end{array}$ \\
\hline ASD & $\begin{array}{l}\text { Direito et al. } \\
2021\end{array}$ & Adult & $\begin{array}{l}\text { ASD-related symptomatology } \\
(\mathrm{N}=8)\end{array}$ & $\uparrow \mathrm{STS}$ & No control group & FEEST & $\begin{array}{l}\text { Nsession }=5 / \\
\text { Nruns }=4\end{array}$ & No & Yes (6 months) & $\begin{array}{l}\text { Intermittent/ Emotion } \\
\text { recognition task }\end{array}$ \\
\hline ASD & $\begin{array}{l}\text { Ramot et al. } \\
2013\end{array}$ & $\begin{array}{l}\text { Adolescents - } \\
\text { Adult }\end{array}$ & No & $\begin{array}{l}\text { 个 left STS - SCC } \\
\text { connectivity }\end{array}$ & $\begin{array}{l}\text { Healthy control group } \\
(\mathrm{N}=10) \text { : feedback from } \\
\text { other regions (STS - IPL } \\
\text { connectivity) }\end{array}$ & SRS & $\begin{array}{l}\text { Nsession }=4 \text { / } \\
\text { Nrun }=4\end{array}$ & No & $\begin{array}{l}\text { Yes }(5 \text { - } 56 \\
\text { weeks / EG = } \\
\text { 15) }\end{array}$ & $\begin{array}{l}\text { Continuous/ Puzzle } \\
\text { task }\end{array}$ \\
\hline $\begin{array}{l}\text { Alcohol } \\
\text { use } \\
\text { disorder }\end{array}$ & $\begin{array}{l}\text { Karch et al. } \\
2015\end{array}$ & Adult & Not clearly reported & $\downarrow \operatorname{DLPFC}(\mathrm{N}=13)$ & $\begin{array}{l}\text { Healthy control group: } \\
\text { one group received } \\
\text { feedback from PFC ( } N= \\
\text { 14) and one group } \\
\text { received feedback from } \\
\text { cuneus }(N=5)\end{array}$ & OCDS & $\begin{array}{l}\text { Nsession }=4 / \\
\text { Nrun }=1\end{array}$ & No & No & $\begin{array}{l}\text { Continuous / Alcohol- } \\
\text { cue induced craving }\end{array}$ \\
\hline
\end{tabular}




\begin{tabular}{|c|c|c|c|c|c|c|c|c|c|c|}
\hline Disorder & Study & Population & $\begin{array}{l}\text { Concomitant Treatment } \\
(\mathrm{EG} / \mathrm{CG})\end{array}$ & $\begin{array}{l}\text { Training target in } \\
\text { experimental group } \\
\text { ( } \mathrm{N} \text { subjects in final } \\
\text { sample) }\end{array}$ & $\begin{array}{l}\text { Training target in } \\
\text { control group (N } \\
\text { subjects in final } \\
\text { sample) }\end{array}$ & $\begin{array}{l}\text { Clinical } \\
\text { outcome } \\
\text { measures }\end{array}$ & $\begin{array}{l}\text { NF training } \\
\text { session number } \\
\text { / runs number }\end{array}$ & $\begin{array}{l}\text { Transfer } \\
\text { run }\end{array}$ & $\begin{array}{l}\text { Follow-up } \\
\text { (duration/ N } \\
\text { sujets) }\end{array}$ & Feedback (type / task) \\
\hline & & & & & $\begin{array}{l}\text { Active control group ( } \mathrm{N} \\
=2 \text { ) : feedback from an } \\
\text { unrelated control } \\
\text { region (cuneus) }\end{array}$ & & & & & \\
\hline & $\begin{array}{l}\text { Subramanian } \\
\text { et al. } 2021\end{array}$ & Adult & $\begin{array}{l}\text { Yes (psycho- education, } \\
\text { psychological support, and } \\
\text { medical management of } \\
\text { abstinence) }\end{array}$ & $\begin{array}{l}\downarrow \text { salience network ( } \\
=20)\end{array}$ & $\begin{array}{l}\text { Passive control group } \\
(\mathrm{N}=27) \text { : treatment as } \\
\text { usual }\end{array}$ & $\begin{array}{l}\text { Alcohol } \\
\text { timeline } \\
\text { followback }\end{array}$ & $\begin{array}{l}\text { Nsession = 6/ } \\
\text { Nruns }=2\end{array}$ & No & $\begin{array}{l}\text { Yes (8-month } \\
\text { and 12-month, } \\
\text { EG = }\end{array}$ & $\begin{array}{l}\text { Continuous / Alcohol- } \\
\text { cue induced craving }\end{array}$ \\
\hline \multirow{2}{*}{$\begin{array}{l}\text { Borderline } \\
\text { personality } \\
\text { disorder }\end{array}$} & $\begin{array}{l}\text { Paret et al. } \\
2016\end{array}$ & Adult & $\begin{array}{l}\text { SSRI (5) + other } \\
\text { antidepressant (5) + } \\
\text { neuroleptica (2) + } \\
\text { methylphenidat, mood } \\
\text { stabilizer or opioid receptor } \\
\text { antagonist (1) }\end{array}$ & $\downarrow$ amygdala $(\mathrm{N}=8)$ & No control group & DERS + DSS & $\begin{array}{l}\text { Nsession = 4 / } \\
\text { Nruns }=3\end{array}$ & Yes & $\begin{array}{l}\text { Yes ( } 3 \text { days } / \\
E G=8)\end{array}$ & $\begin{array}{l}\text { Continuous / watching } \\
\text { negative vs. Neutral } \\
\text { pictures }\end{array}$ \\
\hline & $\begin{array}{l}\text { Zaehringer et } \\
\text { al. } 2019\end{array}$ & Adult & $\begin{array}{l}\text { Psychotropic medication }(\mathrm{N}= \\
26)\end{array}$ & $\downarrow$ amygdala $(\mathrm{N}=26)$ & No control group & $\begin{array}{l}\text { ZAN-BPD + } \\
\text { DERS + SEK- } \\
27\end{array}$ & $\begin{array}{l}\text { Nsession = } 3 / \\
\text { Nruns }=4\end{array}$ & No & $\begin{array}{l}\text { Yes }(6 \text { weeks } / \\
E G=24)\end{array}$ & $\begin{array}{l}\text { Intermittent / } \\
\text { Watching negative vs. } \\
\text { Neutral pictures }\end{array}$ \\
\hline \multirow[t]{2}{*}{ MDD } & $\begin{array}{l}\text { Linden et al. } \\
2012\end{array}$ & Adult & $\begin{array}{l}\text { Antidepressant medication } \\
(\mathrm{N}=8)\end{array}$ & $\begin{array}{l}\uparrow \text { regions involved in } \\
\text { the generation of } \\
\text { positive emotions } \\
\text { (VLPFC and insula) (N } \\
=8)\end{array}$ & $\begin{array}{l}\text { Active control group } \\
\text { (out): Patients } \\
\text { performing mental } \\
\text { imagery of positive } \\
\text { emotions outside the } \\
\text { scanner }(\mathrm{N}=8)\end{array}$ & HDRS & $\begin{array}{l}\text { Nsession }=4 / \\
\text { Nruns }=3\end{array}$ & No & No & $\begin{array}{l}\text { Continuous / positive } \\
\text { mental imagery }\end{array}$ \\
\hline & $\begin{array}{l}\text { Mehler et al. } \\
2018\end{array}$ & Adult & $\begin{array}{l}\text { Antidepressant medication } \\
(\mathrm{N}=32)\end{array}$ & $\begin{array}{l}\uparrow \text { emotion areas }(\mathrm{N}= \\
16)\end{array}$ & $\begin{array}{l}\text { Active control group: } \uparrow \\
\text { control region } \\
\text { activated by visual } \\
\text { scenes }(\mathrm{N}=16)\end{array}$ & HDRS & $\begin{array}{l}\text { Nsessions = } 5 \text { / } \\
\text { Nruns }=6\end{array}$ & Yes & $\begin{array}{l}\text { Yes ( } 1 \text { month } \\
\text { / } E G=13, C G= \\
\text { 13) }\end{array}$ & $\begin{array}{l}\text { Continuous / positive } \\
\text { mental imagery }\end{array}$ \\
\hline
\end{tabular}




\begin{tabular}{|c|c|c|c|c|c|c|c|c|c|c|}
\hline Disorder & Study & Population & $\begin{array}{l}\text { Concomitant Treatment } \\
\text { (EG/CG) }\end{array}$ & $\begin{array}{l}\text { Training target in } \\
\text { experimental group } \\
\text { ( } \mathrm{N} \text { subjects in final } \\
\text { sample) }\end{array}$ & $\begin{array}{l}\text { Training target in } \\
\text { control group (N } \\
\text { subjects in final } \\
\text { sample) }\end{array}$ & $\begin{array}{l}\text { Clinical } \\
\text { outcome } \\
\text { measures }\end{array}$ & $\begin{array}{l}\text { NF training } \\
\text { session number } \\
\text { / runs number }\end{array}$ & $\begin{array}{l}\text { Transfer } \\
\text { run }\end{array}$ & $\begin{array}{l}\text { Follow-up } \\
\text { (duration/ N } \\
\text { sujets) }\end{array}$ & Feedback (type / task) \\
\hline & $\begin{array}{l}\text { Mennen et al. } \\
2021\end{array}$ & Adult & Not clearly reported & $\begin{array}{l}\text { Whole-brain ROI } \\
(\mathrm{N}=15)\end{array}$ & $\begin{array}{l}\text { Healthy control group } \\
(\mathrm{N}=12): \text { whole brain } \\
\text { ROI }\end{array}$ & MADRS & $\begin{array}{l}\text { Nsessions }= \\
3 / \text { Nruns }=7-9\end{array}$ & No & $\begin{array}{l}\text { Yes (1 month } \\
E G=14 / 3 \\
\text { months } E G= \\
13)\end{array}$ & $\begin{array}{l}\text { Intermittent / Visual } \\
\text { negative images }\end{array}$ \\
\hline & $\begin{array}{l}\text { Young et al. } \\
2014\end{array}$ & Adult & No & $\uparrow$ amygdala ( $N=14$ ) & $\begin{array}{l}\text { Active control group ( } \mathrm{N} \\
=7 \text { ): Patients receiving } \\
\text { feedback from an } \\
\text { unrelated region (HIPS) }\end{array}$ & POMS + VAS & $\begin{array}{l}\text { Nsession = } 1 / \\
\text { Nruns }=3\end{array}$ & Yes & No & $\begin{array}{l}\text { Continuous / Recall } \\
\text { positive } \\
\text { autobiographical } \\
\text { memories }\end{array}$ \\
\hline & $\begin{array}{l}\text { Young et al. } \\
2017\end{array}$ & Adult & No & $\uparrow$ amygdala ( $\mathrm{N}=19$ ) & $\begin{array}{l}\text { Active control group ( } \mathrm{N} \\
=17 \text { ): Patients } \\
\text { receiving feedback } \\
\text { from an unrelated } \\
\text { region (HIPS) }\end{array}$ & MADRS & $\begin{array}{l}\text { Nsession = 2/ } \\
\text { Nruns }=3\end{array}$ & Yes & $\begin{array}{l}\text { Yes (1 week/ } \\
E G=18 \mathrm{EG}, \mathrm{CG} \\
=15)\end{array}$ & $\begin{array}{l}\text { Intermittent / Recall } \\
\text { positive } \\
\text { autobiographical } \\
\text { memories }\end{array}$ \\
\hline & $\begin{array}{l}\text { Yuan et al. } \\
2014\end{array}$ & Adult & No & $\uparrow$ amygdala ( $N=14$ ) & $\begin{array}{l}\text { Healthy control group } \\
(\mathrm{N}=27) \text { : Feedback } \\
\text { from the ROI } \\
\text { Active control ( } \mathrm{N}=13) \text { : } \\
\text { Patients receiving } \\
\text { feedback from an } \\
\text { unrelated region (HIPS) }\end{array}$ & $\begin{array}{l}\text { HDRS + } \\
\text { HAM-A }\end{array}$ & $\begin{array}{l}\text { Nsession }=1 / \\
\text { Nruns }=3\end{array}$ & Yes & No & $\begin{array}{l}\text { Continuous / Recall } \\
\text { positive } \\
\text { autobiographical } \\
\text { memories }\end{array}$ \\
\hline & $\begin{array}{l}\text { Zhan et al. } \\
2019\end{array}$ & Adult & No & $\begin{array}{l}\uparrow \text { ATL-SCC } \\
\text { correlations }(N=14)\end{array}$ & $\begin{array}{l}\text { Active control group } \\
(\mathrm{N}=14) \text { : remitted } \\
\text { patients received a } \\
\text { feedback which } \\
\text { stabilized the preceding } \\
\text { degree of correlation }\end{array}$ & $\begin{array}{l}\mathrm{BDI}+\mathrm{IQG}+ \\
\text { RSES }\end{array}$ & $\begin{array}{l}\text { Nsession }=1 / \\
\text { Nruns }=2\end{array}$ & No & No & $\begin{array}{l}\text { Intermittent / } \\
\text { Retrieving guilt and } \\
\text { indignation/anger- } \\
\text { related } \\
\text { autobiographical } \\
\text { memories }\end{array}$ \\
\hline & $\begin{array}{l}\text { Zotev et al. } \\
2016\end{array}$ & Adult & No & $\uparrow$ amygdala ( $\mathrm{N}=13$ ) & $\begin{array}{l}\text { Active control group } \\
(\mathrm{N}=11) \text { : feedback from } \\
\text { an unrelated region } \\
\text { (HIPS) }\end{array}$ & POMS + VAS & $\begin{array}{l}\text { Nsession }=2 / \\
\text { Nruns }=3\end{array}$ & Yes & No & $\begin{array}{l}\text { Continuous / Recall } \\
\text { positive } \\
\text { autobiographical } \\
\text { memories }\end{array}$ \\
\hline
\end{tabular}




\begin{tabular}{|c|c|c|c|c|c|c|c|c|c|c|}
\hline Disorder & Study & Population & $\begin{array}{l}\text { Concomitant Treatment } \\
\text { (EG/CG) }\end{array}$ & $\begin{array}{l}\text { Training target in } \\
\text { experimental group } \\
\text { ( } \mathrm{N} \text { subjects in final } \\
\text { sample) }\end{array}$ & $\begin{array}{l}\text { Training target in } \\
\text { control group (N } \\
\text { subjects in final } \\
\text { sample) }\end{array}$ & $\begin{array}{l}\text { Clinical } \\
\text { outcome } \\
\text { measures }\end{array}$ & $\begin{array}{l}\text { NF training } \\
\text { session number } \\
\text { / runs number }\end{array}$ & $\begin{array}{l}\text { Transfer } \\
\text { run }\end{array}$ & $\begin{array}{l}\text { Follow-up } \\
\text { (duration/ N } \\
\text { sujets) }\end{array}$ & Feedback (type / task) \\
\hline & $\begin{array}{l}\text { Zotev et al. } \\
2020\end{array}$ & Adult & No & $\uparrow$ amygdala (N=16) & $\begin{array}{l}\text { Active control group } \\
(\mathrm{N}=8) \text { : feedback } \\
\text { received from an } \\
\text { unrelated region } \\
\text { (rostro-dorsal ACC) }\end{array}$ & $\begin{array}{l}\text { POMS + VAS } \\
+ \text { STAI }\end{array}$ & $\begin{array}{l}\text { Nsession = } 1 \text { / } \\
\text { Nruns = } 3\end{array}$ & Yes & No & $\begin{array}{l}\text { Continuous / Recall } \\
\text { positive } \\
\text { autobiographical } \\
\text { memories }\end{array}$ \\
\hline & $\begin{array}{l}\text { Takamura et al. } \\
2020\end{array}$ & Adult & Yes $(N=5)$. Type not reported & 个 DLPFC $(\mathrm{N}=6)$ & No control group & $\begin{array}{l}\mathrm{BDI}+\mathrm{HDRS} \\
+\mathrm{RRQ}\end{array}$ & $\begin{array}{l}\text { Nsession }=5 / \\
\text { Nruns }=1-5\end{array}$ & No & No & $\begin{array}{l}\text { Intermittent/Mental } \\
\text { imagery }\end{array}$ \\
\hline & $\begin{array}{l}\text { Tsuchiyagaito } \\
\text { et al. } 2021\end{array}$ & Adult & No & $\uparrow$ amygdala (N=29) & No control group & MADRS & $\begin{array}{l}\text { Nsession = 2/ } \\
\text { Nruns }=3\end{array}$ & Yes & $\begin{array}{l}\text { Yes (2weeks / } \\
\mathrm{N}=29)\end{array}$ & $\begin{array}{l}\text { Intermittent / Recall } \\
\text { positive } \\
\text { autobiographical } \\
\text { memories }\end{array}$ \\
\hline $\begin{array}{l}\text { Nicotine } \\
\text { use } \\
\text { disorder }\end{array}$ & $\begin{array}{l}\text { Hartwell et al. } \\
2016\end{array}$ & Adult & No & $\downarrow \operatorname{PFC}(N=21)$ & $\begin{array}{l}\text { Active control group } \\
(\mathrm{N}=23) \text { : patients } \\
\text { receiving no feedback }\end{array}$ & QSU-B & $\begin{array}{l}\text { Nsession = } 3 / \\
\text { Nruns }=3\end{array}$ & No & $\begin{array}{l}\text { Yes }(1 \text { week } / \\
E G=17, C G= \\
19)\end{array}$ & $\begin{array}{l}\text { Intermittent/ } \\
\text { Smoking-cue exposure } \\
\text { task }\end{array}$ \\
\hline \multirow{5}{*}{ PTSD } & $\begin{array}{l}\text { Gerin et al. } \\
2016\end{array}$ & Adult & No & $\downarrow$ amygdala $(\mathrm{N}=3)$ & No control group & $\begin{array}{l}\text { CAPS + PCL- } \\
M\end{array}$ & $\begin{array}{l}\text { Nsession }=3 / \\
\text { Nruns }=4\end{array}$ & No & No & $\begin{array}{l}\text { Continuous/Hearing of } \\
\text { trauma-related scripts }\end{array}$ \\
\hline & $\begin{array}{l}\text { Misaki et al. } \\
2021\end{array}$ & Adult & Not clearly reported & $\uparrow$ amygdala $(\mathrm{N}=20)$ & $\begin{array}{l}\text { Active control group (N } \\
\text { =9): feedback received } \\
\text { from an unrelated } \\
\text { region (HIPS) }\end{array}$ & $\begin{array}{l}\text { CAPS + } \\
\text { MADRS }\end{array}$ & $\begin{array}{l}\text { Nsession }=7 / \\
\text { Nruns }=4\end{array}$ & Yes & No & $\begin{array}{l}\text { Continuous/ recall a } \\
\text { positive } \\
\text { autobiographical } \\
\text { memory }\end{array}$ \\
\hline & $\begin{array}{l}\text { Nicholson et al. } \\
2017\end{array}$ & Adult & No & $\downarrow$ amygdala $(\mathrm{N}=10)$ & No control group & RSDI & $\begin{array}{l}\text { Nsession = } 3 / \\
\text { Nruns }=4\end{array}$ & Yes & No & $\begin{array}{l}\text { Intermittent/ } \\
\text { Watching trauma- } \\
\text { related vs neutral } \\
\text { words }\end{array}$ \\
\hline & $\begin{array}{l}\text { Zweering et al. } \\
2018\end{array}$ & Adult & Not clearly reported & $\uparrow A C C(N=9)$ & $\begin{array}{l}\text { Healthy control group } \\
(\mathrm{N}=9) \text { : feedback from } \\
\text { the ROI }\end{array}$ & $\begin{array}{l}\text { IES-R + } \\
\text { PANAS-X }\end{array}$ & $\begin{array}{l}\text { Nsession = } 3 / \\
\text { Nruns }=1\end{array}$ & Yes & No & $\begin{array}{l}\text { Continuous/ Mental } \\
\text { imagery }\end{array}$ \\
\hline & $\begin{array}{l}\text { Zotev et al. } \\
2018\end{array}$ & Adult & No & $\uparrow$ amygdala $(\mathrm{N}=20)$ & $\begin{array}{l}\text { Active control group ( } N \\
=11 \text { ): feedback } \\
\text { received from an } \\
\text { unrelated region (HIPS) }\end{array}$ & CAPS + HDRS & $\begin{array}{l}\text { Nsession = 3/ } \\
\text { Nruns }=3\end{array}$ & Yes & No & $\begin{array}{l}\text { Continuous / Happy } \\
\text { emotion induction }\end{array}$ \\
\hline
\end{tabular}




\begin{tabular}{|c|c|c|c|c|c|c|c|c|c|c|}
\hline Disorder & Study & Population & $\begin{array}{l}\text { Concomitant Treatment } \\
\text { (EG/CG) }\end{array}$ & $\begin{array}{l}\text { Training target in } \\
\text { experimental group } \\
\text { ( } \mathrm{N} \text { subjects in final } \\
\text { sample) }\end{array}$ & $\begin{array}{l}\text { Training target in } \\
\text { control group (N } \\
\text { subjects in final } \\
\text { sample) }\end{array}$ & $\begin{array}{l}\text { Clinical } \\
\text { outcome } \\
\text { measures }\end{array}$ & $\begin{array}{l}\text { NF training } \\
\text { session number } \\
\text { / runs number }\end{array}$ & $\begin{array}{l}\text { Transfer } \\
\text { run }\end{array}$ & $\begin{array}{l}\text { Follow-up } \\
\text { (duration/ N } \\
\text { sujets) }\end{array}$ & Feedback (type / task) \\
\hline \multirow{5}{*}{ SCZ } & $\begin{array}{l}\text { Bauer et al. } \\
2020\end{array}$ & Adult & Antipsychotic & $\begin{array}{l}\downarrow \text { DMN connectivity } \\
(\mathrm{N}=11)+\mathrm{SMC} \\
\text { connectivity (control } \\
\text { region) }\end{array}$ & No control group & AHRS & $\begin{array}{l}\text { Nsession }=2 / \\
\text { Nruns }=4\end{array}$ & Yes & $\begin{array}{l}\text { Yes (1 week/ } \\
\text { EG = 11) }\end{array}$ & $\begin{array}{l}\text { Continuous/Mental } \\
\text { noting task }\end{array}$ \\
\hline & $\begin{array}{l}\text { Dyck et al. } \\
2016\end{array}$ & Adult & Antipsychotic $(\mathrm{N}=2)$ & $\uparrow A C C(N=3)$ & No control group & $\begin{array}{l}\text { AVHRS + } \\
\text { PANAS }\end{array}$ & $\begin{array}{l}\text { Nsession }=3 / \\
\text { Nruns }=1\end{array}$ & Yes & No & $\begin{array}{l}\text { Continuous/ Mental } \\
\text { imagery }\end{array}$ \\
\hline & $\begin{array}{l}\text { Okano et al. } \\
2020\end{array}$ & Adult & Antipsychotic & $\begin{array}{l}\downarrow \mathrm{STG}(\mathrm{N}=10)+\mathrm{SCC} \\
\text { (control region) }\end{array}$ & No control group & AHRS & $\begin{array}{l}\text { Nsession }=2 / \\
\text { Nruns }=6\end{array}$ & Yes & $\begin{array}{l}\text { Yes (1 week / } \\
\text { EG =10) }\end{array}$ & $\begin{array}{l}\text { Continuous/ Hearing } \\
\text { AVH - provoking } \\
\text { stimuli }\end{array}$ \\
\hline & $\begin{array}{l}\text { Orlov et al. } \\
2019\end{array}$ & Adult & Antipsychotic & $\downarrow \mathrm{STG}(\mathrm{N}=11)$ & No control group & Psyrats & $\begin{array}{l}\text { Nsession = 4/ } \\
\text { Nruns = 1-6 }\end{array}$ & Yes & $\begin{array}{l}\text { Yes (1 week/ } \\
\text { EG = 11) }\end{array}$ & $\begin{array}{l}\text { Continuous / Voice } \\
\text { perception task }\end{array}$ \\
\hline & Ruiz et al. 2013 & Adult & Antipsychotic & $\begin{array}{l}\uparrow \text { anterior insula ( } N= \\
9)\end{array}$ & No control group & PANAS & $\begin{array}{l}\text { Nsession }=12 / \\
\text { Nrun }=1\end{array}$ & Yes & No & $\begin{array}{l}\text { Continuous/ Face } \\
\text { emotion recognition }\end{array}$ \\
\hline
\end{tabular}

$\uparrow=$ upregulation; $\downarrow=$ downregulation; $\mathrm{N}=$ sample size; $\mathrm{EG}=$ Experimental group; $\mathrm{CG}=$ Control group

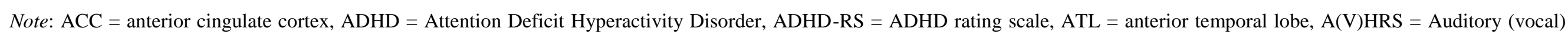

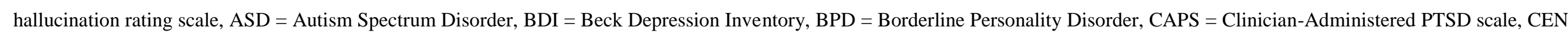

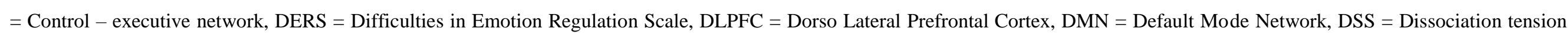

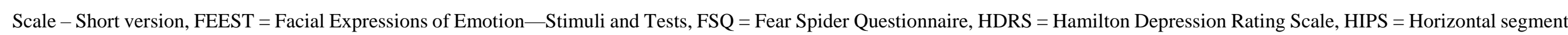

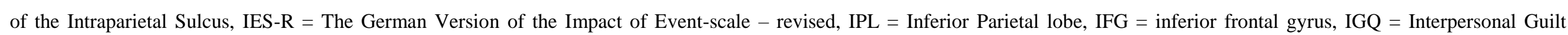

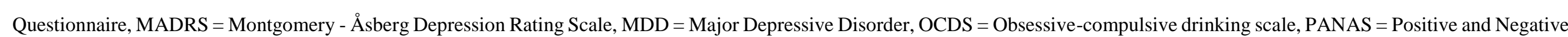

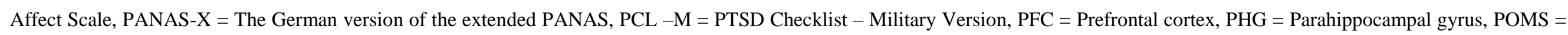

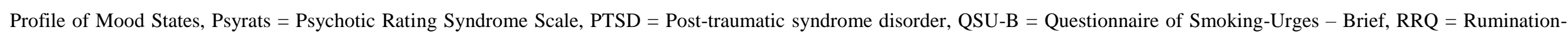

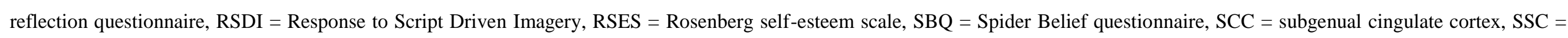

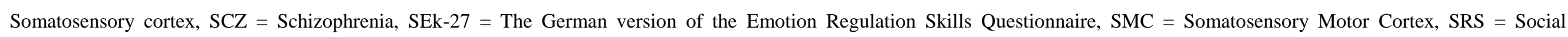

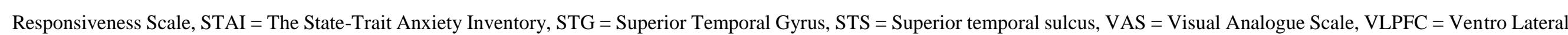
Prefrontal Cortex, ZAN-BPD = The Zanarini rating scale for borderline personality disorders 
Table 2. Clinical improvement in primary outcomes measures post-NF and at follow-up

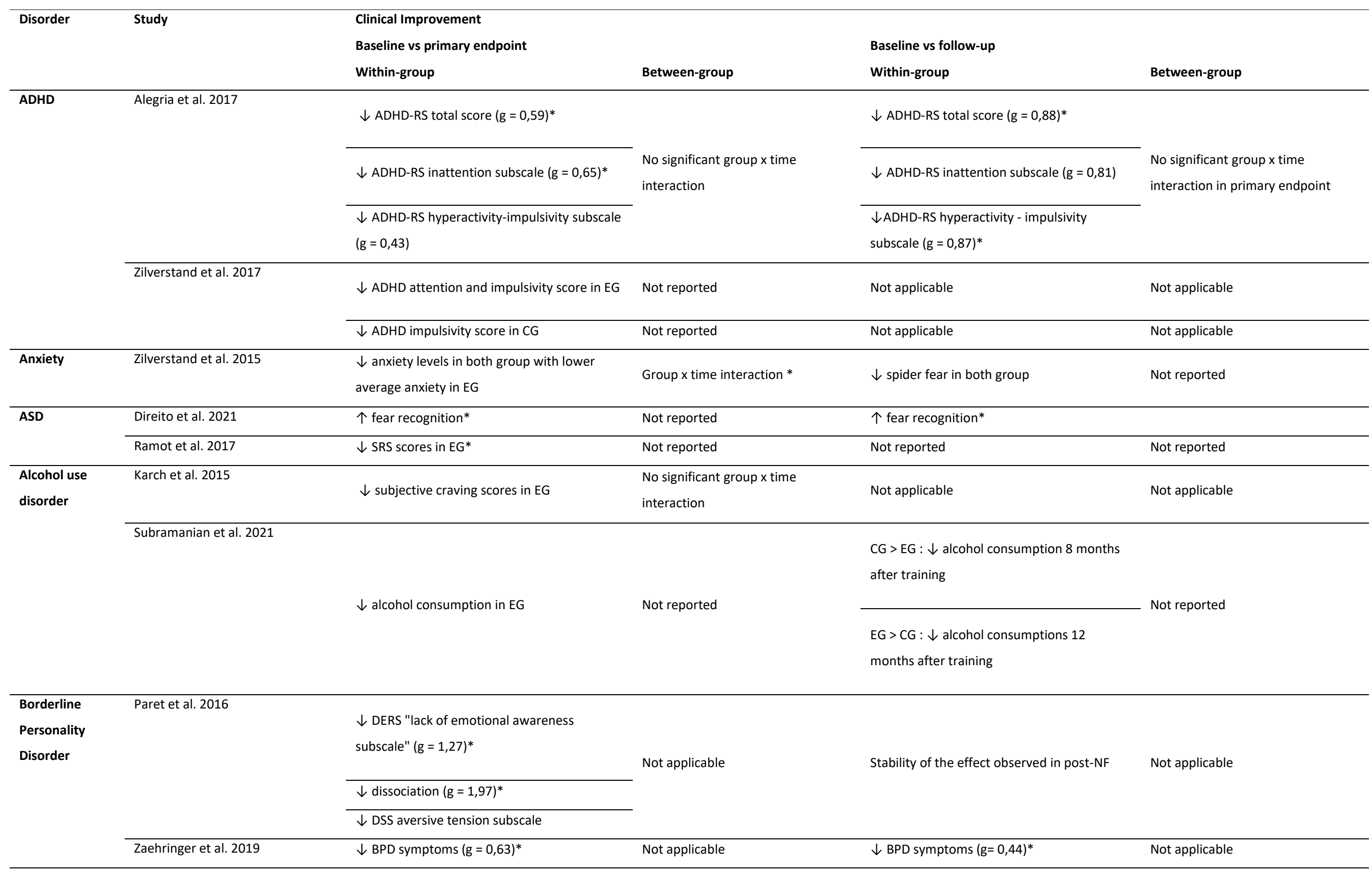




\begin{tabular}{|c|c|c|c|c|c|}
\hline \multirow[t]{5}{*}{ Disorder } & \multirow[t]{5}{*}{ Study } & \multicolumn{4}{|l|}{ Clinical Improvement } \\
\hline & & \multicolumn{2}{|l|}{ Baseline vs primary endpoint } & \multicolumn{2}{|l|}{ Baseline vs follow-up } \\
\hline & & Within-group & Between-group & Within-group & Between-group \\
\hline & & \multirow{2}{*}{ Non-significant $\downarrow$ Emotion dysregulation } & & $\downarrow$ Emotion dysregulation $(g=0,47)^{*}$ & \\
\hline & & & & 个 Emotional skills $(g=-0,54)^{*}$ & \\
\hline \multirow[t]{14}{*}{ MDD } & Linden et al. 2012 & $\begin{array}{l}\downarrow \text { depressive symptoms in experimental } \\
\text { group }(\mathrm{g}=1.33)^{*}\end{array}$ & Group $x$ time interaction for HDRS * & Not applicable & Not applicable \\
\hline & Mehler et al. 2018 & $\downarrow$ HDRS in both groups (CG: $g=2.16$; EG: $g=$ & \multirow{3}{*}{$\begin{array}{l}\text { No significant group } \mathrm{x} \text { time } \\
\text { interaction }\end{array}$} & 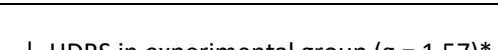 & \multirow{3}{*}{ No significant effects } \\
\hline & & $2.23)^{*}$ & & $\downarrow$ HDKS in experimental group $(g=1,5 /)$ & \\
\hline & & $\begin{array}{l}\downarrow \text { anxiety levels and depressive levels in both } \\
\text { groups }\end{array}$ & & $\begin{array}{l}\downarrow \text { anxiety levels and depressive levels in } \\
\text { both groups }\end{array}$ & \\
\hline & Mennen et al. 2021 & $\downarrow$ depressive ratings (g=1.28)* & Not reported & $\begin{array}{l}\downarrow \text { depressive ratings at 1-month ( } g=1.05) \\
\text { and 3-months follow-up ( } g=1.30)\end{array}$ & Not reported \\
\hline & Young et al. 2014 & $\begin{array}{l}\downarrow \text { POMS depression subscale and anger } \\
\text { subscale in EG }(g=0.50)^{*}\end{array}$ & \multirow{4}{*}{$\begin{array}{l}\text { EG > control group: } \uparrow \text { VAS } \\
\text { happiness }(g=0.36)^{*}\end{array}$} & \multirow{4}{*}{ Not applicable } & \multirow{4}{*}{ Not applicable } \\
\hline & & 个 VAS hapiness rating & & & \\
\hline & & $\begin{array}{l}\downarrow \text { VAS restlessness, anxiety and irritated } \\
\text { subscale }\end{array}$ & & & \\
\hline & & $\downarrow$ VAS sadness subscale in CG & & & \\
\hline & Young et al. 2017 & & & & \\
\hline & & $\downarrow$ Depressive symptoms in $\mathrm{EG}(\mathrm{g}=1.17)^{*}$ & $\begin{array}{l}\text { EG > CG: Group } x \text { time interaction } \\
\text { for MADRS }(g=1.13)^{*}\end{array}$ & $\downarrow$ MADRS $(g=0,58)^{*}$ & $\begin{array}{l}\underline{E G>C G:} \downarrow \text { MADRS }(g=1.14)^{*}, \text { BDI- } \\
\text { II }(g=0.72)^{*}, \text { HAM-D }(g=0.90)^{*}\end{array}$ \\
\hline & Yuan et al. 2014 & $\begin{array}{l}\downarrow \text { HARS }(g=0.66) \text { and HDRS }(g=0.61) \text { scores } \\
\text { in EG and active control group }\end{array}$ & Not reported & Not applicable & Not applicable \\
\hline & Zahn et al. 2019 & $\downarrow$ self-hate and $\uparrow$ self-esteem in EG & Group $\mathrm{x}$ time interaction for RSES* & Not applicable & Not applicable \\
\hline & Zotev et al. 2016 & $\begin{array}{l}\downarrow \text { POMS depressive scores, mood } \\
\text { disturbance scores and } \uparrow \text { VAS hapiness* }\end{array}$ & $\begin{array}{l}\underline{\mathrm{EG}>\mathrm{CG}}: \downarrow \text { POMS depressive } \\
\text { scores }(g=0.03)^{*}\end{array}$ & Not applicable & Not applicable \\
\hline
\end{tabular}




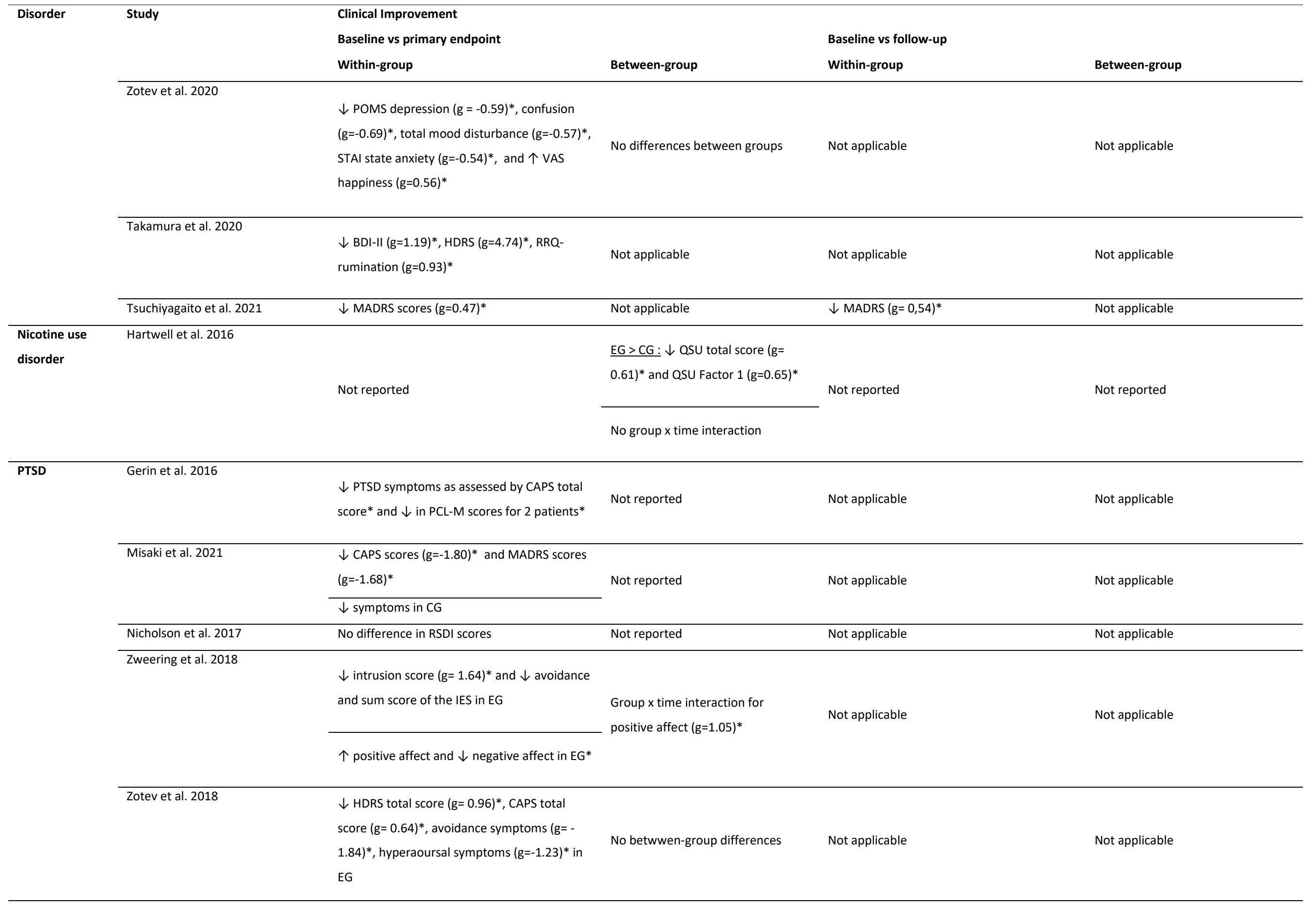




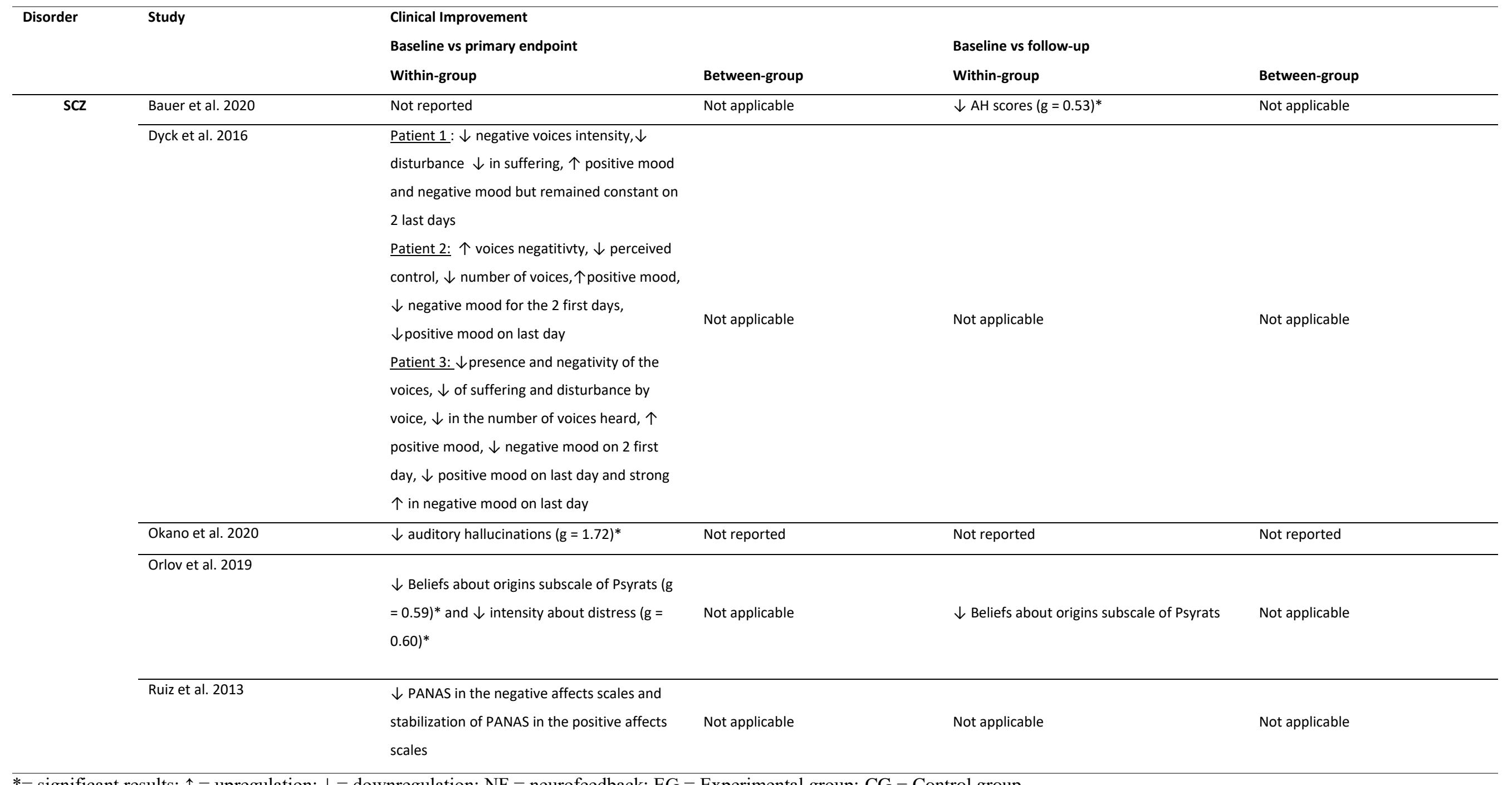

*= significant results; $\uparrow=$ upregulation; $\downarrow=$ downregulation; $\mathrm{NF}=$ neurofeedback; $\mathrm{EG}=$ Experimental group; $\mathrm{CG}=$ Control group

Note $:$ ADHD-RS $=$ ADHD rating scale, A(V)HRS = Auditory $($ vocal) hallucination rating scale, AAUD $=$ Alcohol Use Disorder, $\mathrm{BDI}=\mathrm{Beck}$ Depression Inventory, BPD $=$ Borderline Personality Disorder, CAPS = Clinician-Administered PTSD scale, DERS $=$ Difficulties in Emotion Regulation Scale, DMN $=$ Default Mode Network, DSS $=$ Dissociation tension Scale Short version, HARS = Hamilton Anxiety Rating Scale, HDRS $=$ Hamilton Depression Rating Scale, HIPS = Horizontal segment of the Intraparietal Sulcus, IES-R $=$ The German Version of the Impact of Event-scale - revised, MADRS = Montgomery - Åsberg Depression Rating Scale, MDD = Major Depressive Disorder, PANAS = Positive and Negative Affect Scale, PCL $-\mathrm{M}$ = PTSD Checklist - Military Version, POMS = Profile of Mood States, Psyrats = Psychotic Rating Syndrome Scale, PTSD = Post-traumatic syndrome disorder, QSU-B = Questionnaire of Smoking-Urges - Brief, RRQ = Rumination-reflection questionnaire, RSDI = Response to Script Driven Imagery, RSES = Rosenberg self-esteem scale, $\mathrm{SCZ}=\mathrm{Schizophrenia}, \mathrm{SRS}=\mathrm{Social}$ Responsiveness Scale, STAI = The State-Trait Anxiety Inventory, VAS = Visual Analogue Scale, ZAN-BPD = The Zanarini rating scale for borderline personality disorder 
Table 3. Clinical improvement in secondary outcome measures

\begin{tabular}{|c|c|c|c|c|c|}
\hline \multirow[t]{3}{*}{ Disorder } & \multirow[t]{3}{*}{ Study } & \multicolumn{4}{|l|}{ Other significant outcomes } \\
\hline & & \multicolumn{2}{|l|}{ Post- NF (compared to baseline) } & \multicolumn{2}{|l|}{ Follow-up (compared to baseline } \\
\hline & & Within-group & Between-group & Within-group & Between-group \\
\hline \multirow[t]{4}{*}{ ADHD } & \multirow[t]{2}{*}{ Alegria et al. 2017} & $\begin{array}{l}\downarrow A D H D \text { severity (measured with CPRS) in } \\
\text { both groups }\end{array}$ & $\begin{array}{l}\text { No significant time } \mathrm{x} \text { group } \\
\text { interaction }\end{array}$ & Not reported & Not reported \\
\hline & & $\begin{array}{l}\text { Control group }: \downarrow \text { ADHD-related difficulties } \\
\text { and functional impairments * }\end{array}$ & $\begin{array}{l}\text { No significant time } \mathrm{x} \text { group } \\
\text { interaction }\end{array}$ & Not reported & Not reported \\
\hline & \multirow[t]{2}{*}{ Zilverstand et al. 2017} & $\uparrow$ cognitive interference task in both group & Not reported & Not applicable & Not applicable \\
\hline & & $\begin{array}{l}\text { Experimental group: } \uparrow \text { response inhibition } \\
\text { and } \uparrow \text { in visual working memory }\end{array}$ & Not reported & Not applicable & Not applicable \\
\hline ASD & Ramot et al., 2017 & $\begin{array}{l}\downarrow \text { depressive score }+\downarrow \text { POMS tension }+\downarrow \\
\text { POMS anger }\end{array}$ & Not reported & Not reported & Not reported \\
\hline \multirow[t]{2}{*}{ AUD } & Karch et al. 2015 & No changes in BRIEF & Not reported & Not reported & Not reported \\
\hline & Subramanian et al. 2021 & $\begin{array}{l}\text { Not reported } \\
\text { EG >CG : } \downarrow \text { alcohol craving }\end{array}$ & $\begin{array}{l}\text { Not reported } \\
\text { Not reported }\end{array}$ & $\begin{array}{l}\text { Not applicable } \\
\text { Not reported }\end{array}$ & $\begin{array}{l}\text { Not applicable } \\
\text { Not reported }\end{array}$ \\
\hline BPD & Zaehringer et al. 2019 & CG $>E G: \downarrow$ alcohol stroop interference & $\begin{array}{l}\text { No significant group } x \text { time } \\
\text { interaction } \\
\text { Not reported } \\
\text { Not reported }\end{array}$ & $\begin{array}{l}\text { Not applicable } \\
\text { CG }>\text { EG }: \downarrow \text { alcohol } \\
\text { consumption } 8 \text { months after } \\
\text { training } \\
\downarrow \text { Alexithymia symptoms }\end{array}$ & $\begin{array}{l}\text { Not applicable } \\
\text { Not reported } \\
\text { Not reported }\end{array}$ \\
\hline MDD & Linden et al. 2012 & $\downarrow$ affective instability & $\begin{array}{l}\text { Group x Time interaction for } \\
\text { POMS* } \\
\text { Not applicable } \\
\text { No significant time x group } \\
\text { interaction in POMS }\end{array}$ & $\begin{array}{l}\text { EG }>C G: \downarrow \text { alcohol } \\
\text { consumptions } 12 \text { months after } \\
\text { training } \\
\text { Stability of the effect observed } \\
\text { in post-NF } \\
\text { Not applicable }\end{array}$ & $\begin{array}{l}\text { Not applicable } \\
\text { Not applicable } \\
\text { Not applicable }\end{array}$ \\
\hline
\end{tabular}




$\begin{array}{ll}\text { Study } & \text { Other significant outcomes } \\ & \text { Post- NF (compared to baseline) }\end{array}$

Post- NF (compared to baseline)

Follow-up (compared to baseline

Within-group

$\downarrow$ negative affect in $\mathrm{EG}$

\begin{tabular}{lll}
\hline Young et al. 2017 & $\downarrow$ STAI State subscale and Trait subscale in \\
& EG* & $\begin{array}{l}\text { State Anxiety were } \\
\text { significantly } \downarrow \text { in EG } \\
\text { (comapred to CG)* }\end{array}$ \\
\hline
\end{tabular}

Not applicable

$\downarrow$ HAM-A $(d=0,86),{ }^{*}$, HAM-D $\quad$ Not applicable

EG: $\downarrow$ BDI-II $(d=1.09)^{*}$, HAM-A $(d=1.04)^{*}$

$\underline{E G>C G:} \downarrow B D I-I I(d=0.71)^{*}$,

$(d=1.19)^{*}, B D I-I I(d=1.09)^{*}$

EG >CG $: \downarrow$ SHAPS $(d=0.54)^{*}$

SHAPS $(d=0.54)^{*}$

HAM-D $(d=0.66)^{*}$
SHAPS $(d=0.83)^{*}$
$\underline{E G>C G:} \downarrow$ BDI-II $(d=0.71)^{*}$, HAM-D $(d=0.66)^{*}$

\begin{tabular}{|c|c|c|c|c|}
\hline Zahn et al. 2019 & $\underline{\mathrm{CG}}: \downarrow$ HAM-A $(\mathrm{d}=0.89)^{*}$ & $\begin{array}{l}\underline{E G>C G:} \downarrow \text { BDI-II }(\mathrm{d}=0.71)^{*}, \\
\operatorname{HAM}-\mathrm{D}(\mathrm{d}=0.66)^{*}\end{array}$ & $\begin{array}{l}\downarrow \text { Emotion dysregulation }(\mathrm{d}= \\
0,49)^{*}\end{array}$ & Not applicable \\
\hline \multirow[t]{2}{*}{ Zotev et al. 2020} & & $\uparrow$ ATL-SCC correlation in the & & \\
\hline & $\begin{array}{l}\uparrow \text { ATL-SCC correlation in EG for guilt vs. } \\
\text { Indignation }\end{array}$ & $\begin{array}{l}\text { EG post-training (vs. Pre- } \\
\text { training) compared to CG for } \\
\text { guilt vs. Indignation }\end{array}$ & Not applicable & Not applicable \\
\hline
\end{tabular}

$\uparrow=$ upregulation; $\downarrow=$ downregulation, $\mathrm{NF}=$ neurofeedback, $\mathrm{EG}=$ experimental group, $\mathrm{CG}=$ control group, $\mathrm{NF}=$ neurofeedback

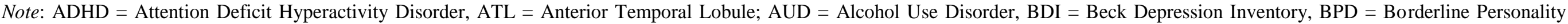

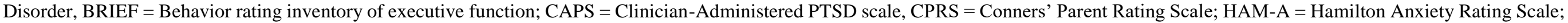

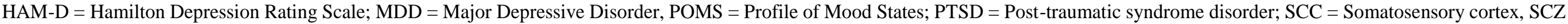
$=$ Schizophrenia; SHAPS = Snaith-Hamilton Pleasure Scale, STAI = The State-Trait Anxiety Inventory, 
Table 4. Robustness of included studies

\begin{tabular}{|c|c|c|c|c|c|c|c|}
\hline Disorder & Study & Type of blinded studies & Randomization & Number of NF training session & Number of NF training runs & Control $(\mathrm{Y} / \mathrm{N})$ & Type of control \\
\hline \multirow{2}{*}{ ADHD } & Alegria et al. 2017 & Single-blinded & $Y$ & 4 & 3 or 4 & $Y$ & Contingent sham \\
\hline & Zilverstand et al. 2017 & Single-blinded & $\mathrm{Y}$ & 4 & 3 & Y & No feedback \\
\hline Anxiety & Zilverstand et al. 2015 & Single-blinded & $\mathrm{Y}$ & 1 & 4 & $\mathrm{Y}$ & No feedback \\
\hline ASD & Ramot et al. 2017 & Single-blinded & $\mathrm{N}$ & 4 & 4 & $\mathrm{Y}$ & Contingent sham \\
\hline \multirow[t]{2}{*}{ AUD } & Karch et al. 2015 & $\mathrm{~N}$ & $\mathrm{~N}$ & 4 & 1 & Y & $\begin{array}{c}\text { Healthy control and } \\
\text { contingent sham }\end{array}$ \\
\hline & Subramanian et al. 2021 & $\mathrm{~N}$ & $\mathrm{Y}$ & 6 & 2 & $\mathrm{Y}$ & Passive control TAU \\
\hline BPD & Paret et al. 2016 & $\mathrm{~N}$ & $\mathrm{~N}$ & 4 & 3 & $\mathrm{~N}$ & - \\
\hline \multirow{9}{*}{ MDD } & Linden et al. 2012 & $\mathrm{~N}$ & $\mathrm{~N}$ & 4 & 3 & $\mathrm{Y}$ & Imagery control \\
\hline & Mehler et al. 2018 & Single-blinded & $Y$ & 2 & 6 & $Y$ & Contingent sham \\
\hline & Mennen et al. 2021 & $\mathrm{~N}$ & $\mathrm{~N}$ & 3 & 7 to 9 & $Y$ & Healthy control \\
\hline & Young et al. 2014 & Double-blinded & $\mathrm{N}$ & 1 & 3 & $Y$ & Contingent sham \\
\hline & Young et al. 2017 & Double-blinded & $Y$ & 2 & 3 & $Y$ & Contingent sham \\
\hline & Yuan et al. 2014 & Double-blinded & $\mathrm{N}$ & 1 & 3 & $Y$ & $\begin{array}{c}\text { Healthy control and } \\
\text { contingent sham }\end{array}$ \\
\hline & Zahn et al. 2019 & Double-blinded & $Y$ & 1 & 2 & $Y$ & $\begin{array}{c}\text { Stabilization as } \\
\text { control intervention }\end{array}$ \\
\hline & Zotev et al. 2016 & $\mathrm{~N}$ & $\mathrm{~N}$ & 2 & 3 & $\mathrm{Y}$ & Contingent sham \\
\hline & Zotev et al. 2020 & $\mathrm{~N}$ & $\mathrm{~N}$ & 1 & 3 & $\mathrm{Y}$ & Contingent sham \\
\hline NUD & Hartwell et al. 2016 & $\mathrm{~N}$ & $Y$ & 3 & 3 & $\mathrm{Y}$ & No feedback \\
\hline PTSD & Gerin et al. 2016 & $\mathrm{~N}$ & $\mathrm{~N}$ & 3 & 4 & $\mathrm{~N}$ & - \\
\hline
\end{tabular}




\begin{tabular}{|c|c|c|c|c|c|c|c|}
\hline & Misaki et al., 2021 & Single-blinded & $\mathrm{Y}$ & 7 & 4 & $\mathrm{Y}$ & Contingent \\
\hline & Nicholson et al. 2017 & $\mathrm{~N}$ & $\mathrm{~N}$ & 3 & 4 & $\mathrm{~N}$ & - \\
\hline & Zotev et al. 2018 & $\mathrm{~N}$ & $\mathrm{Y}$ & 3 & 3 & $\mathrm{Y}$ & Contingent sham \\
\hline \multirow{4}{*}{ SCZ } & Bauer et al. 2020 & $\mathrm{~N}$ & $\mathrm{~N}$ & 2 & 4 & $\mathrm{Y}$ & Cross over \\
\hline & Dyck et al. & $\mathrm{N}$ & $\mathrm{N}$ & 3 & 1 & $\mathrm{~N}$ & - \\
\hline & Orlov et al. & $\mathrm{N}$ & $\mathrm{N}$ & 4 & 1 to 6 & $\mathrm{~N}$ & - \\
\hline & Ruiz et al. 2013 & $\mathrm{~N}$ & $\mathrm{~N}$ & 12 & 1 & $\mathrm{~N}$ & - \\
\hline
\end{tabular}

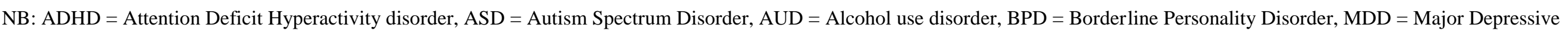
Disorder, NUD = Nicotine Use disorder, PTSD = post-traumatic syndrome disorder, $\mathrm{SCZ}=$ Schizophrenia 
Table 5. Studies included in the meta-analysis

\begin{tabular}{|c|c|c|c|c|c|}
\hline Study & Disorder & Within-experimental group & Between-group & Follow-up & $\begin{array}{l}\text { Type of } \\
\text { control }\end{array}$ \\
\hline Zilverstand et al. 2015 & Anxiety & $\downarrow$ anxiety level $(g=0.95)$ & Group* time interaction $(\mathrm{g}=2.59$ ) & $\downarrow$ spider fear in both group $(g=1.22)$ & Active \\
\hline \multirow[t]{3}{*}{ Paret et al. 2015} & BPD & J DFRS "lack of emotional awareness subscale" ( $\sigma=127)^{*}$ & \multirow{3}{*}{ Not applicable } & \multirow{3}{*}{ Stability of the effect observed in post-NF } & \multirow{3}{*}{$\begin{array}{l}\text { No control } \\
\text { group }\end{array}$} \\
\hline & & $\downarrow$ dissociation $(g=1,97)^{*}$ & & & \\
\hline & & $\downarrow$ DSS aversive tension subscale & & & \\
\hline \multirow[t]{3}{*}{ Zaehringer et al. 2019} & BPD & $\downarrow$ BPD symptoms $(\mathrm{g}=0,63)^{*}$ & \multirow{3}{*}{ Not applicable } & $\downarrow$ BPD symptoms $(g=0,44)^{*}$ & \multirow{3}{*}{ Active } \\
\hline & & \multirow{2}{*}{ No-significant $\downarrow$ Emotion dysregulation } & & $\downarrow$ Emotion dysregulation $(\mathrm{g}=0,47)^{*}$ & \\
\hline & & & & 个 Emotional skills $(g=-0,54)^{*}$ & \\
\hline \multirow[t]{2}{*}{ Linden et al. 2012} & MDD & & & & \multirow[b]{2}{*}{ Active } \\
\hline & & $\downarrow$ depressive symptoms in experimental group $(g=1.33)^{*}$ & Group* time interaction $(g=1.51)$ & Not applicable & \\
\hline \multirow[t]{4}{*}{ Mehler et al. 2018} & MDD & & \multirow{4}{*}{ No significant group $\mathrm{x}$ time interaction } & & \multirow{4}{*}{ Active } \\
\hline & & $\downarrow$ HDRS in both groups (CG: $g=2.16$; EG: $g=2.23)^{*}$ & & $\downarrow$ HDRS in experimental group $(g=1,57)^{*}$ & \\
\hline & & & & & \\
\hline & & $\downarrow$ anxiety levels and depressive levels in both groups & & $\begin{array}{l}\downarrow \text { anxiety levels and depressive levels in } \\
\text { both groups }\end{array}$ & \\
\hline \multirow[t]{2}{*}{ Mennen et al. 2021} & MDD & & \multirow{3}{*}{ Not reported } & \multirow[b]{2}{*}{$\begin{array}{l}\downarrow \text { depressive ratings at } 1 \text {-month ( } \mathrm{g}=1.05) \\
\text { and 3-months follow-up ( } \mathrm{g}=1.30 \text { ) }\end{array}$} & \\
\hline & & $\downarrow$ depressive ratings $(\mathrm{g}=1.28)^{*}$ & & & Active \\
\hline \multirow[t]{4}{*}{ Young et al. 2014} & MDD & & & \multirow{4}{*}{ Not applicable } & \multirow{4}{*}{ Active } \\
\hline & & $\downarrow$ POMS depression subscale and anger subscale in EG $(g=0.50)^{*}$ & \multirow{3}{*}{$\underline{\text { EG > control group: }} \uparrow$ VAS happiness $(g=0.36)^{*}$} & & \\
\hline & & 个 VAS hapiness rating & & & \\
\hline & & $\downarrow$ VAS restlessness, anxiety and irritated subscale & & & \\
\hline
\end{tabular}




\begin{tabular}{|c|c|c|c|c|c|}
\hline & & $\downarrow$ VAS sadness subscale in CG & & & \\
\hline \multirow[t]{2}{*}{ Young et al. 2017} & MDD & & & & \\
\hline & & $\downarrow$ Depressive symptoms in EG (g=1.17)* & $\begin{array}{l}\text { EG >CG: Group } x \text { time interaction for MADRS } \\
(\mathrm{g}=1.13)^{*}\end{array}$ & $\downarrow$ MADRS $(g=0,58)^{*}$ & Active \\
\hline \multirow[t]{2}{*}{ Yuan et al. 2014} & MDD & & & & \\
\hline & & $\begin{array}{l}\downarrow \text { HARS }(g=0.66) \text { and HDRS scores }(g=0.61) \text { in EG and active control } \\
\text { group }\end{array}$ & $\begin{array}{l}\text { No significant group } \mathrm{x} \text { time interaction in HARS } \\
\text { and HDRS }\end{array}$ & Not applicable & Not applicable \\
\hline \multirow[t]{2}{*}{ Zahn et al. 2019} & MDD & & & & \\
\hline & & No significant BDI improvement $(g=0)$ & No group*time interaction in BDI & Not applicable & Active \\
\hline \multirow[t]{3}{*}{ Zotev et al. 2016} & MDD & & & & \\
\hline & & $\downarrow$ POMS depressive scores $(\mathrm{g}=0.51)$ & $\underline{\mathrm{EG}}>\mathrm{CG}: \downarrow$ POMS depressive scores* $(\mathrm{g}=0.03)$ & & Active \\
\hline & & & & Not applicable & \\
\hline Zotev et al. 2020 & MDD & $\begin{array}{l}\downarrow \text { POMS depression }(g=-0.59)^{*} \text {, confusion }(g=-0.69)^{*} \text {, total mood } \\
\text { disturbance }(g=-0.57)^{*} \text {, STAl state anxiety }(g=-0.54)^{*} \text {, and } \uparrow \text { VAS } \\
\text { happiness }(g=0.56)^{*}\end{array}$ & No group*time interaction in POMS & Not applicable & Active \\
\hline Takamura et al. 2020 & MDD & $\downarrow \mathrm{BDI}-\mathrm{II}(\mathrm{g}=1.19)^{*}$ & Not applicable & Not applicable & $\begin{array}{l}\text { No control } \\
\text { group }\end{array}$ \\
\hline Tsuchiyagaito et al. 2021 & MDD & $\downarrow$ MADRS scores $(g=0.47)^{*}$ & Not applicable & $\downarrow$ MADRS $(g=0,54)^{*}$ & $\begin{array}{l}\text { No control } \\
\text { group }\end{array}$ \\
\hline \multirow[t]{3}{*}{ Misaki et al. 2021} & PTSD & & & & \\
\hline & & $\downarrow$ MADRS scores $(\mathrm{g}=-1.68)^{*}$ & No group*time interaction in MADRS & & Active \\
\hline & & & & Not applicable & \\
\hline \multirow[t]{3}{*}{ Zweering et al. 2018} & PTSD & & & & \\
\hline & & $\uparrow$ positive affect $(g=0.67)$ and $\downarrow$ negative affect in $\mathrm{EG}(\mathrm{g}=0.27)^{*}$ & $\begin{array}{l}\text { Group* time interaction for positive affect }(\mathrm{g}= \\
1.05)^{*}\end{array}$ & & Active \\
\hline & & & & Not applicable & \\
\hline \multirow[t]{3}{*}{ Zotev et al. 2018} & PTSD & & & & \\
\hline & & $\downarrow$ HDRS total score $(g=0.96)$ & No group*time interaction in HDRS & & Active \\
\hline & & & & Not applicable & \\
\hline
\end{tabular}

\section{$\uparrow=$ upregulation; $\downarrow=$ downregulation; $C G=$ Control Group EG = Experimental Group}

Note BDI = Beck Depression Inventory, BPD = Borderline Personality Disorder, CAPS = Clinician-Administered PTSD scale, HARS = Hamilton Anxiety Rating Scale, MDD = Major Depressive Disorder, POMS = Profile of Mood States; PTSD = post-traumatic syndrome disorder; STAI = The State-Trait Anxiety Inventory, VAS = Visual Analogue Scale 